\title{
Genetic and Molecular Basis of Heterogeneous NK Cell Responses against Acute Leukemia
}

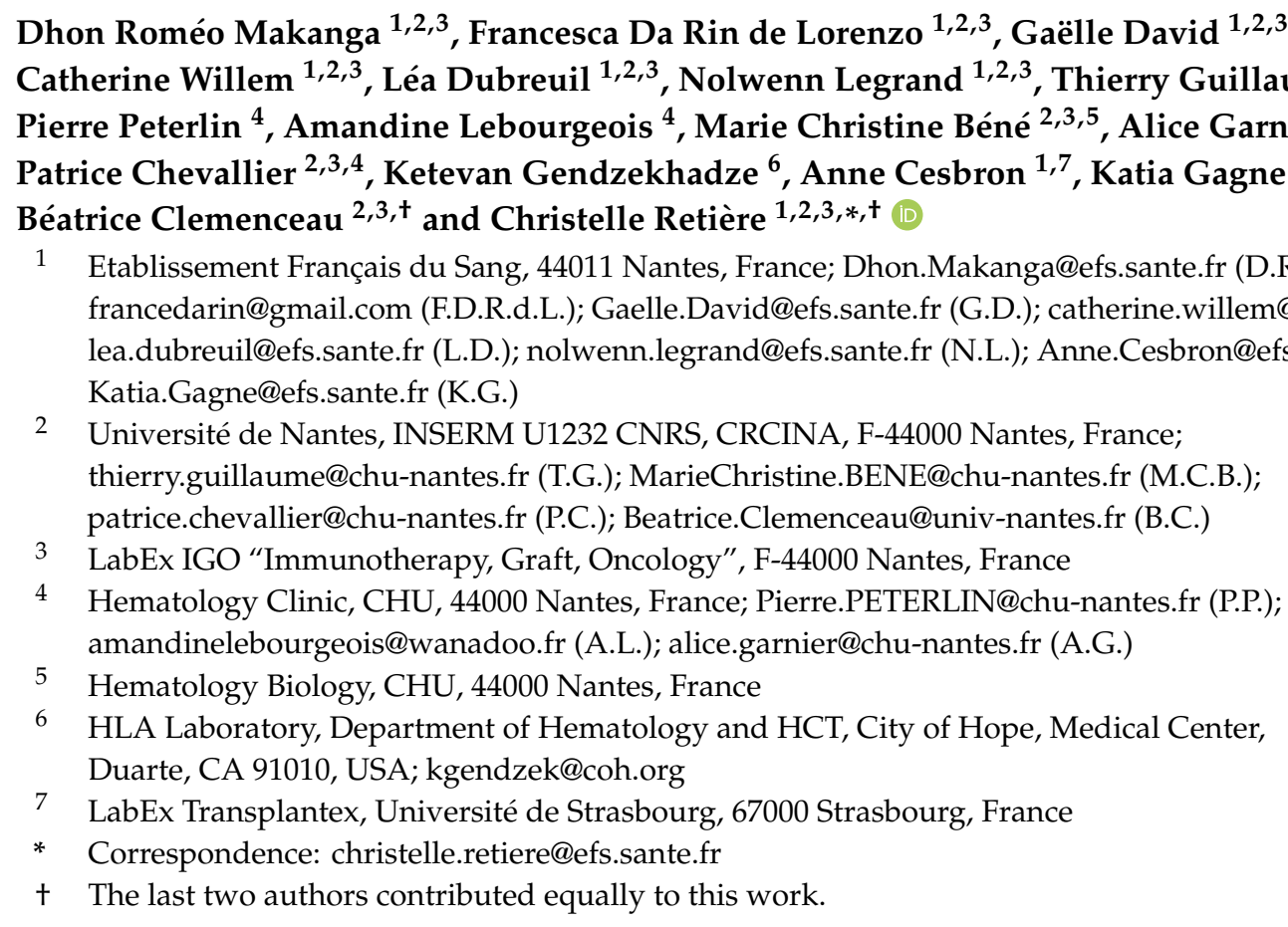

Received: 22 June 2020; Accepted: 13 July 2020; Published: 16 July 2020

\begin{abstract}
Natural killer (NK) cells are key cytotoxic effectors against malignant cells. Polygenic and polymorphic Killer cell Immunoglobulin-like Receptor (KIR) and HLA genes participate in the structural and functional formation of the NK cell repertoire. In this study, we extensively investigated the anti-leukemic potential of NK cell subsets, taking into account these genetic parameters and cytomegalovirus (CMV) status. Hierarchical clustering analysis of NK cell subsets based on NKG2A, KIR, CD57 and NKG2C markers from 68 blood donors identified donor clusters characterized by a specific phenotypic NK cell repertoire linked to a particular immunogenetic KIR and HLA profile and CMV status. On the functional side, acute lymphoblastic leukemia (ALL) was better recognized by NK cells than acute myeloid leukemia (AML). However, a broad inter-individual disparity of NK cell responses exists against the same leukemic target, highlighting bad and good NK responders. The most effective NK cell subsets against different ALLs expressed NKG2A and represented the most frequent subset in the NK cell repertoire. In contrast, minority CD $57^{+}$or/and $\mathrm{KIR}^{+} \mathrm{NK}$ cell subsets were more efficient against AML. Overall, our data may help to optimize the selection of hematopoietic stem cell donors on the basis of immunogenetic KIR/HLA for ALL patients and identify the best NK cell candidates in immunotherapy for AML.
\end{abstract}

Keywords: KIR; HLA; natural killer cells; repertoire; acute leukemia; CMV

\section{Introduction}

Natural killer (NK) cells are key cytotoxic effectors of innate immunity against malignant [1] and virally infected cells [2]. They are able to sense the absence or the low expression of HLA 
class I molecules on cancer or virally infected cells via Killer cell Immunoglobulin-like Receptor (KIR) [3]. On the basis of their recognition of HLA class I, a strong interest in NK cells is focused on hematopoietic stem cell transplantation (HSCT) to optimize the graft-versus-leukemia (GvL) effect. In the context of acute leukemias, NK cell-mediated immunosurveillance requires the establishment of an immunological synapse between the NK cell and the leukemia target, involving a large number of interactions between inhibitory and activating NK receptors and their ligands expressed by leukemic cells. Inhibitory receptors mainly include KIR and NKG2A receptors, which are specific to HLA class I molecules. KIRs are clonally expressed on the surface of mature NK cells. In addition, inhibitory KIRs and autologous HLA class I interactions contribute to the functional education of NK cells [4]. Thus, only $\mathrm{KIR}^{+} \mathrm{NK}$ cells that have encountered their ligand during development will be educated to recognize their absence [5]. The inhibitory NKG2A receptor is expressed on the surface of immature NK cells and ensures NK cell-mediated immunosurveillance through interaction with the HLA-E molecule [6] before KIR expression. Moreover, NK cells express a wide range of activating receptors that recognize induced or upregulated molecules on tumor cells. Activating NK receptors known to be involved in NK cell activation include NKG2D, DNAM-1, 2B4 and NCRs such as NKp30, NKp44 and NKp46. NKG2D recognizes MICA/B and ULBP ligands, DNAM-1 recognizes PVR and Nectin-2 ligands, and 2B4 recognizes CD48 [7]. NCRs recognize different ligands on the cell membrane that can be induced in response to stress or pathogen infection [8-11] (Table 1). Cognate ligands are heterogeneously expressed on leukemias. It has been reported that the absence of expression or downregulation of HLA class I molecules, as well as the presence of activating ligands on the surface of leukemia cells, were associated with the reduction of relapse incidence and improved overall survival of patients with leukemia [12,13].

Table 1. Main inhibitory and activating NK cell receptors and their cognate ligands.

\begin{tabular}{ccc}
\hline NK Receptors & CD Number & Ligands \\
DNAM-1 & CD226 & Activating \\
2B4 & CD244 & Nectin-2 (CD112), PVR(CD155) \\
NKp30 & CD337 & CD48 \\
NKp44 & CD336 & B7-H6, BAT3 a , PfEMP1 a \\
NKp46 & CD335 & CFP a , viral HA, HN ${ }^{\text {a }}$ or envelope proteins, PfEMP1 a \\
NKG2D & CD314 & MIC-A ${ }^{\text {a }}$, MIC-B $^{\text {a }}$, ULBP1-6 \\
NKG2C & CD159a & HLA-E \\
NKG2A & CD159a & Inhibitory \\
KIR2DL2/3 & CD158b & HLA-E \\
\hline
\end{tabular}

a PVR, poliovirus receptor; BAT3, HLA-B-associated transcript 3; PfEMP1, Plasmodium falciparum erythrocyte membrane protein 1; PCNA, proliferating cell nuclear antigen; HS, heparan sulfate; CFP, Complement factor P; $\mathrm{HA}$, haemagglutinin; HN, haemagglutinin neuramidase; MIC, major histocompatibility complex (MHC) class I polypeptide-related sequence. ${ }^{\mathrm{b}}$ KIR2DL2/L3 also weakly recognizes HLA-C2 alleles and few HLA-B alleles that bear the HLA-C1 epitope (e.g., HLA-B*4601 and HLA-B*7301).

We previously documented the beneficial role of KIR and HLA incompatibilities between the donor and the recipient, which significantly limited relapse in the context of haploidentical HSCT [14]. We showed that KIR and HLA incompatibilities participate in the activation and earlier differentiation of NK cells associated with more graft-versus-host-disease (GvHD) and less relapse [14]. However, we are not yet able to define the most effective NK cell populations against leukemia, depending on the nature of acute lymphoblastic or myeloid leukemia.

KIR and HLA genes participate in the structural and functional formation of the NK cell repertoire. The KIR and HLA gene families constitute the most polymorphic and polygenic receptor-ligand pair in humans, and their functional interactions drive tremendous NK cell diversity with a limited number of germline-encoded genes [15]. According to the NK cell differentiation model described by Bjorsktrom et al. [16], NK cell subsets can be defined on the basis of early differentiation markers, 
such as NKG2A and KIR, and the terminal differentiation CD57 marker [17]. Indeed, during their development, immature CD56 ${ }^{\text {bright }}$ NK cells express NKG2A and then gradually lose the intensity of expression of CD56, resulting in a pool of CD56 $\mathrm{dim}$ NK cells $[18,19]$. At this stage, NK cells can lose the expression of NKG2A and/or acquire KIR and/or CD57 markers in a non-coordinated manner, leading to mature CD56 ${ }^{\text {dim }}$ NK cell subsets. Human cytomegalovirus (CMV) drastically changes the NK cell repertoire, favoring a massive and lifelong expansion of adaptive-like NK cells that express activating CD94/NKG2C receptors; these cells constitute the most mature subset [20-22]. These amplified $\mathrm{NKG} \mathrm{C}^{+} \mathrm{NK}$ cells preferentially co-express inhibitory KIR, such as KIR2DL2/3 or KIR2DL1, which is involved in functional NK cell education [23]. Of note, peptide-specific recognition of CMV strains controls adaptive NK cells, which, in part, explains why all CMV seropositive individuals do not display this expanded memory-like NK subset [24].

In this study, we hypothesized that KIR and HLA immunogenetic markers and CMV status drive the NK cell subset distribution and that NK cell subsets do not share similar degranulation potential against leukemias, depending on the nature thereof. Thus, we carried out an in-depth investigation of the anti-leukemic potential of NK cell subsets against a panel of acute myeloid and lymphoid leukemia cell lines and primary leukemic cells, taking into account KIR and HLA genetic parameters, NK cell development stages and the CMV status of healthy blood donors.

\section{Results}

\subsection{Lymphoid Cell Lines More Strongly Stimulated NK Cell Degranulation than Myeloid Cell Lines}

To explore the diversity of the anti-leukemia potential of NK cells, we initially investigated NK cell degranulation from a validation cohort of healthy blood donors $(n=14)$ against a panel of myeloid and lymphoid cell lines (Figure 1A). Lymphoid cell lines, including Burkitt cell lines and acute lymphoblastic leukemia (ALL), more strongly triggered NK cell degranulation than myeloid cell lines, which mainly included acute myeloid leukemia (AML) cell lines (Figure 1A). Given the diversity of NK cell responses based on the target cell nature, we aimed to characterize the phenotype of all target cell lines for the expression of NK receptor ligands known to be involved in the modulation of NK cell functions. Thus, we determined the expression of HLA class I and HLA-E, which are ligands of inhibitor NK receptors, and ULBP1-6, MICA/B, Nectin-2 (CD112), PVR (CD155), CD48 and B7-H6, which are ligands of activating NK receptors. Hierarchical clustering analysis of ligand expression was performed with the Genesis ${ }^{\circledR}$ software, taking into account the mean fluorescence intensity (MFI) of each NK receptor ligand (Figure 1B). Two clusters of target cells can be identified according to trends based on lymphoid and myeloid origins. The first cluster, which mainly includes lymphoid cell lines (except for KG1), showed higher expression of HLA class I, HLA-E, ULBP1/2/5/6 and CD48 ligands than myeloid cell lines. The second cluster, which mainly includes myeloid cell lines (excluding HP Ball), showed higher expression of ULBP3/4, MICA/B, Nectin-2 (CD112) and PVR (CD155) ligands than lymphoid cells (Figure 1B). This dichotomy of ligand expression between myeloid and lymphoid cells leads to different receptor-ligand interactions between NK cells and their cellular targets.

To undertake our study on a broader cohort of healthy donors, we focused our investigation on H9, an acute lymphoblastic leukemia (ALL) cell line, and KG1, an acute myeloid leukemia (AML) cell line, as two representative cell lines that are differently recognized by NK cells.

According to the immunophenotypic analysis, the H9 ALL cell line expressed more ULBP2/5/6, CD48 and B7-H6 than the KG1 AML cell line, which, in contrast, expressed Nectin-2 (CD112) and $\mathrm{MICA} / \mathrm{B}$, which were slightly expressed and not expressed on the $\mathrm{H} 9$ cell line, respectively (Figure S1). Both H9 and KG1 target cells similarly expressed activating ULBP1 and PVR (CD155) ligands (Figure S1). The expression (MFI) of activating NKG2D (Figure 1C), DNAM-1 (Figure 1D) and 2B4 (Figure 1E) were significantly more downregulated on H9 than those on KG1-stimulated NK cells compared with steady-state. These results suggest that activating NKG2D, DNAM-1 and 2B4 receptors were potentially more engaged with their cognate ligands expressed on H9 ALL. 

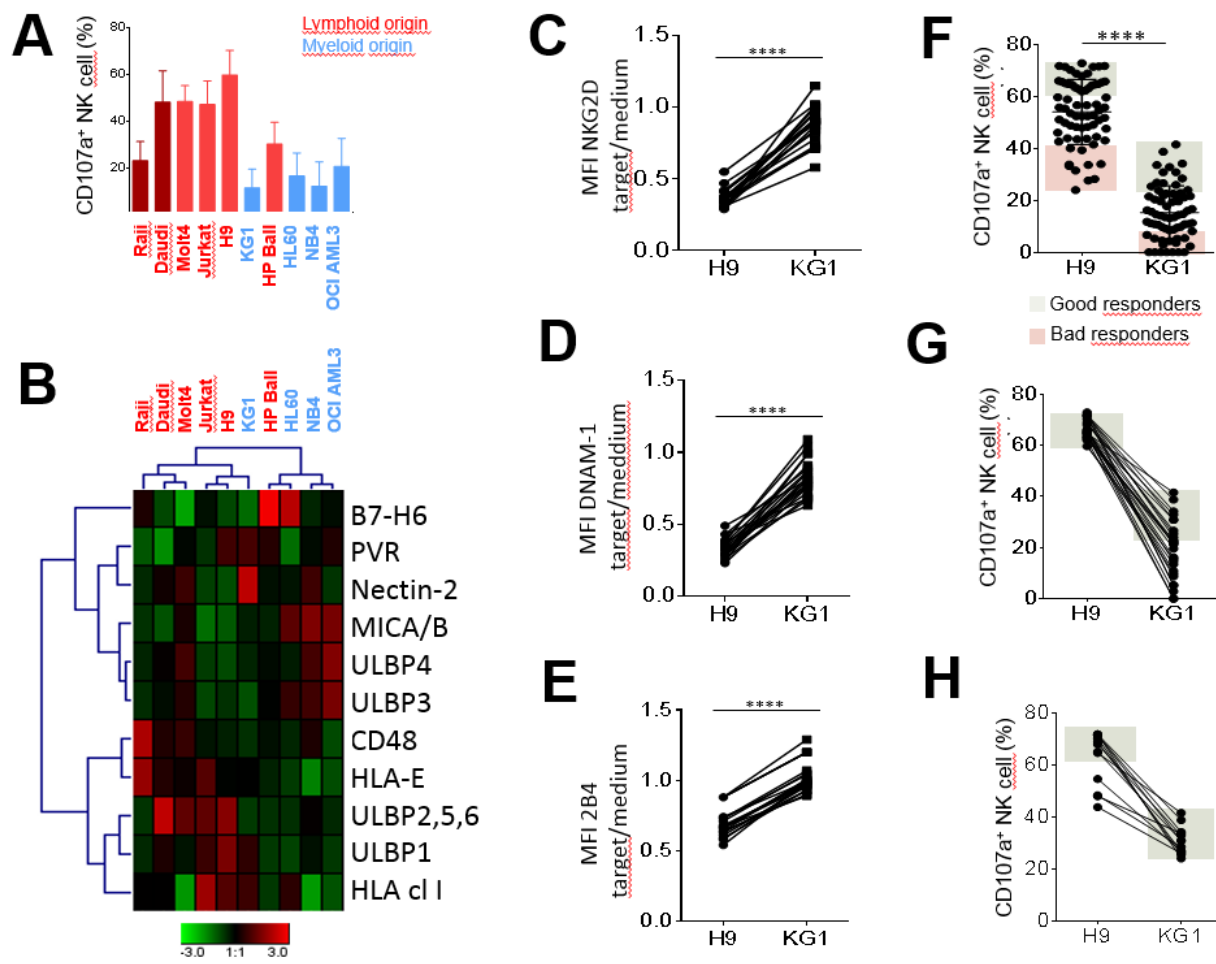

D

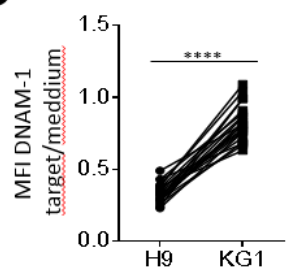

E

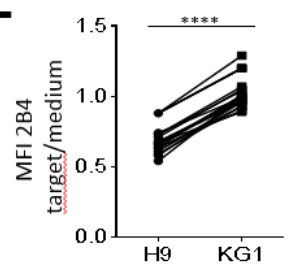

$\mathbf{G}$

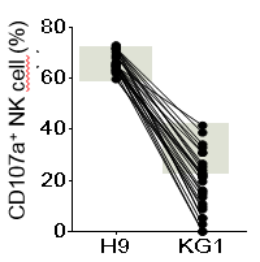

H

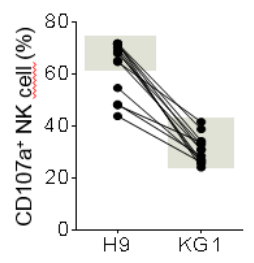

Figure 1. Inter- and intra-individual heterogeneity of NK cell responses against a panel of myeloid and lymphoid target cells. (A) Histogram outlining NK $\left(\mathrm{CD}^{-} \mathrm{CD}^{-} 6^{+}\right)$cell degranulation observed after $5 \mathrm{~h}$ incubation in the presence of myeloid cell lines (blue bar) and lymphoid cell lines (red bar) at an effector/target ratio of 1:1 for 14 representative blood donors. Values are expressed as mean \pm SD. (B) Heatmap representing the relative MFI of each NK ligand expression on target cell surfaces using Genesis software. Relative MFI represents the ratio of the MFI of each NK ligand on the MFI of isotype control of each $\mathrm{mAb}$. Red and green indicate high expression levels and low expression levels, respectively. The modulation of NKG2D (C), DNAM-1 (D) and 2B4 (E) expression observed after NK cell stimulation in the presence of H9 ALL and KG1 AML cell lines at an effector/target ratio 1:1 from 24 representative healthy blood donors by MFC. (F) NK cell degranulation evaluated against H9 ALL and KG1 AML cell lines from a broader cohort of 68 blood donors. Good and bad responders are located in gray and pink zones, respectively. (G) NK cell degranulation against $\mathrm{H} 9$ and $\mathrm{KG1}$ cell lines is represented for good responders identified against H9. (H) NK cell degranulation against H9 and KG1 cell lines is represented for good responders identified against KG1. ${ }^{* * * *}$ Indicates $p<0.0001$ (Student's $t$-test).

\subsection{Inter-Individual Diversity of NK Cell Responses against Leukemia Target Cells}

We further addressed the inter-individual diversity of NK cell responses from a broader cohort of 68 healthy blood donors. We showed that the H9 ALL cell line stimulated NK cell degranulation to a significantly greater extent than the KG1 AML cell line, highlighting bad and good responders against both target cell lines (Figure 1F). In addition, the best responders against H9 were not systematically good responders against KG1 (Figure 1G), and inversely, good responders against KG1 were not all good responders against $\mathrm{H} 9$ (Figure $1 \mathrm{H}$ ). Our results show a broad inter-individual diversity of NK cell responses against leukemic cells. Moreover, NK cell responsiveness was dependent on the nature of leukemic cells, suggesting that different NK cell subsets are engaged depending on the nature of leukemic cells. These observations led us to explore the intra-individual diversity of NK cell responses.

\subsection{The Significant Impact of Immunogenetic HLA/KIR Polymorphisms and CMV Status on the Phenotypic Structuration of the NK Cell Repertoire}

To further investigate the intra-individual diversity of NK cell responses, we refined our investigations to take into account immunogenetic KIR/HLA polymorphisms and CMV status. 
According to the NK cell differentiation model described by Bjorkstrom et al. [16], we defined NK cell subsets on the basis of NK cell maturation stages [18] by targeting NKG2A, KIR2DL2/3 (denoted hereon as KIR), NKG2C and CD57 markers (Figure S2A), and we determined the frequency of each NK cell subset by multiparameter flow cytometry (MFC) from 68 healthy blood donors, who were divided according to KIR and HLA genetics and CMV status (Figure S2B). We found that NKG2A ${ }^{+} \mathrm{KIR}^{-} \mathrm{CD} 57^{-}$ and NKG2 $\mathrm{A}^{-} \mathrm{KIR}^{-} \mathrm{CD} 57^{-} \mathrm{NK}$ cells were the two main subsets in terms of frequency, while NK cell subsets expressing KIR and CD57 markers were represented in low proportions (Figure S2C).

Hierarchical clustering analysis of the NK cell repertoire by Genesis ${ }^{\circledR}$ software led us to identify nine clusters of individuals based on NK cell frequencies (Figure 2A). Each cluster was characterized by a specific NK cell repertoire (Figure 2B) linked to a particular genetic KIR and HLA profile and CMV status (Figure 2C). Thus, $\mathrm{B}^{+}$KIR genotypes favored a higher frequency of NKG2A $\mathrm{A}^{+} \mathrm{KIR}^{+} \mathrm{NK}$ cell subsets compared with AA KIR genotypes; the A3/A11 environment favored higher frequencies of mature CD57 ${ }^{+}$ and $\mathrm{CD} 57^{+} \mathrm{KIR}^{+} \mathrm{NK}$ cells; $\mathrm{C} 2 \mathrm{C} 2$ and Bw4 environments favored a higher frequency $\mathrm{NKG} 2 \mathrm{~A}^{+} \mathrm{KIR}^{-} \mathrm{CD}_{57}{ }^{-}$ $\mathrm{NK}$ cells, and a higher frequency of $\mathrm{NKG} 2 \mathrm{~A}^{+} \mathrm{CD} 57^{+} \mathrm{KIR}^{-} \mathrm{NK}$ cells was favored in the Bw4 environment (Figure 2D). In accordance with the literature, the $\mathrm{NKG}_{2} \mathrm{C}^{+} \mathrm{NK}$ cell frequency was significantly higher in $\mathrm{CMV}^{+}$individuals (Figure 2D). Overall, we observed that each NK cell subset was favored by a specific KIR genotype and/or HLA class I environment or by the presence of CMV.
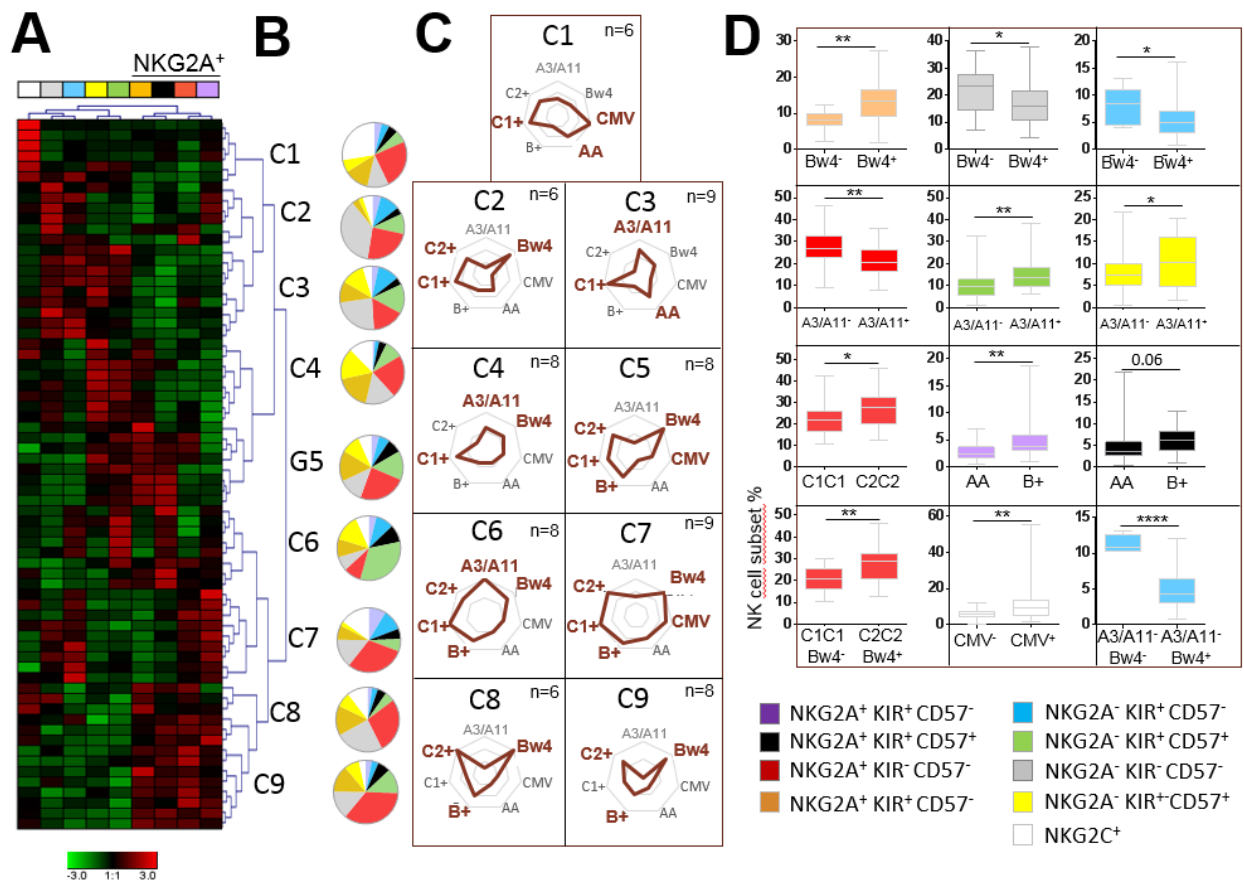

Figure 2. Impact of the immunogenetic KIR/HLA profile and CMV status on the structuration of the NK cell repertoire. (A) Heatmap (Genesis ${ }^{\circledR}$ ) clustering of healthy blood donors $(n=68)$ from the frequency of nine NK cell subsets targeted by flow cytometry based on NKG2A, KIR, NKG2C and CD57 markers. Each column is dedicated to a defined NK cell subset. Red and green indicate the high and low frequencies of the NK cell subsets, respectively. C1-C9 indicate the nine clusters of individuals. (B) Charts representing frequencies of nine investigated NK cell subsets for each cluster. (C) Radar charts indicating the number of blood donors for each characteristic (KIR AA or B ${ }^{+}$genotype, A3/A11, Bw4, C1 and C2 environment and CMV status) per cluster. The KIR/HLA immunogenetic profiles and CMV status impacting each cluster are indicated in brown. (D) Whisker graphs of NK cell subset frequencies according to A3/A11, Bw4, C1, and C2 environments, KIR genotype (AA or $\mathrm{B}^{+}$) and CMV status investigated in 68 individuals. ${ }^{*}$ Indicates $p<0.05,{ }^{* *}$ indicates $p<0.01$ and ${ }^{* * * *}$ indicates $p<0.0001$. 


\subsection{NKG2A+ NK Cell Subsets are the Most Efficient against ALL Target Cells}

We carried out an in-depth investigation of the degranulation of NK cell subsets from 68 healthy blood donors against the H9 ALL cell line. Because all $\mathrm{CMV}^{+}$individuals $(\mathrm{n}=32)$ from our cohort of healthy blood donors did not necessarily exhibit the amplification of $\mathrm{NKG}_{2} \mathrm{C}^{+} \mathrm{NK}$ cells, we excluded the NKG2C marker in this part of the study to define eight NK cell subsets on the basis of NKG2A, KIR and CD57 expression. Hierarchical clustering analysis (Genesis ${ }^{\circledR}$ ) of the degranulation of eight NK cell subsets stimulated with the H9 cell line defined six clusters of individuals (Figure 3A). The superposition of all clusters depending on the immunogenetic KIR and HLA environment and CMV status highlighted specific profiles (Figure 3B). We observed a disparity of whole NK cell degranulation of different clusters, outlining good ( $\mathrm{C} 1, \mathrm{C} 3$ and $\mathrm{C} 4$ clusters) and bad responders $(\mathrm{C} 2$, C5 and C6 clusters), with a significant difference between C1 and C5 (66.40\% versus $42.33 \%, p<0.01)$ and $C 4$ and $C 5$ clusters (56.82\% versus $42.33 \%, p<0.05$ ) (Figure $3 C$ ). Overall, we observed that $\mathrm{CMV}^{-}$ KIR2DS1 ${ }^{-}$individuals were the best responders against the H9 ALL cell line $(59.35 \%$ versus $50.12 \%$, $p=0.0047$ ) (Figure 3D). The shared attribute among the most effective NK cell subset against the H9 cell was NKG2A expression (Figure 3E). Interestingly, the degranulation of each NK cell subset in each individual cluster showed that the NKG2A ${ }^{+} \mathrm{KIR}^{-} \mathrm{CD} 57^{-} \mathrm{NK}$ cell subset was efficient in all clusters (Figure 3F). Of note, NKG2A ${ }^{+} \mathrm{KIR}^{-} \mathrm{CD} 57^{-} \mathrm{NK}$ cell frequency significantly correlated with the degranulation of whole NK cells $(p<0.0001)$ (Figure 3G). This result is in accordance with the prevalence of the NKG2 $\mathrm{A}^{+} \mathrm{KIR}^{-} \mathrm{CD} 57^{-} \mathrm{NK}$ cell subset in the NK cell repertoire.

We further investigated the degranulation potential of NK cell subsets against COE-B primary ALL blasts isolated from a patient. Hierarchical clustering analysis of the degranulation of NK cell subsets from 51 healthy blood donors determined six clusters of individuals (Figure S3A). We observed a disparity of whole NK cell degranulation of different clusters (Figure S3B). The best NK responders were $\mathrm{C} 2 \mathrm{C} 2$ individuals $(24.90 \% \mathrm{C} 1 \mathrm{C} 1,23.11 \% \mathrm{C} 1 \mathrm{C} 2$ and $34.06 \% \mathrm{C} 2 \mathrm{C} 2$ individuals; $p=0.014$ between $\mathrm{C} 1 \mathrm{C} 1$ and $\mathrm{C} 2 \mathrm{C} 2$ individuals, $p=0.004$ between $\mathrm{C} 1 \mathrm{C} 2$ and $\mathrm{C} 2 \mathrm{C} 2$ individuals) (Figure S3C). As observed with the H9 ALL cell line, the most effective NK cell subsets against primary ALL blasts expressed NKG2A (Figure S3D). NKG2A ${ }^{+} \mathrm{KIR}^{-} \mathrm{CD} 57^{-} \mathrm{NK}$ cell frequency significantly correlated with the degranulation of the whole NK cells $(p<0.0001)$ (Figure S3E). Overall, the best NK responders present a $\mathrm{C} 2 \mathrm{C} 2$ environment that favors a high frequency of NKG2A ${ }^{+} \mathrm{KIR}^{-} \mathrm{CD} 57^{-} \mathrm{NK}$ cells, the most efficient NK cells against ALL blasts.

\section{5. $\mathrm{KIR}^{+}$and $\mathrm{CD} 57^{+} \mathrm{NK}$ Cell Subsets are the Most Efficient against AML Target Cells}

In parallel to our investigations on NK cell responses against ALL targets, we carried out an in-depth evaluation of these responses against the AML KG1 cell line and two primary AML blasts from the cohort of 68 healthy blood donors. After KG1 stimulation, we determined eight individual clusters based on the degranulation of the eight studied NK cell subsets using hierarchical clustering analysis (data not shown). C1, C2, C3 and C5 individual clusters presented a strong whole NK cell degranulation in contrast to $\mathrm{C} 4, \mathrm{C} 6, \mathrm{C} 7$ and C8 individual clusters $(p<0.0001)$ (Figure 4A). Interestingly, good responders $(\mathrm{C} 1, \mathrm{C} 2, \mathrm{C} 3$ and $\mathrm{C} 5)$ were predominantly $\mathrm{C} 1 \mathrm{C} 2(p=0.0021)$ in contrast to bad responders (C4, C6, C7 and C8) (Figure 4B). We did not observe an impact of the KIR (AA versus B+) genotype, HLA-A3/A11 and HLA-Bw4 environments or CMV status on whole NK cell degranulation against the KG1 AML cell line (Figure 4C). However, in accordance with the profile of the best NK responders, $\mathrm{C} 1 \mathrm{C} 2$ individuals were better responders against $\mathrm{KG} 1$ compared with $\mathrm{C} 1 \mathrm{C} 1$ individuals (30.74\% versus $20.47 \%, p=0.0038$ ) (Figure $4 \mathrm{C}$ ). Moreover, among C1C2 individuals, AA KIR genotyped individuals were significantly better responders than B+ KIR genotyped individuals (36.08\% versus $26.47 \%, p=0.0082$ ) (Figure 4C). The most effective NK cell subsets against the KG1 AML cell line shared the CD57 marker, as observed in good (whole NK cell degranulation $>20 \%$ ) and bad responders (whole NK cell degranulation $<20 \%$ ) and all studied donors (Figure $4 \mathrm{D}$ ). In focusing on the frequency of studied NK cell subsets, a significant difference was observed between good and bad responders for

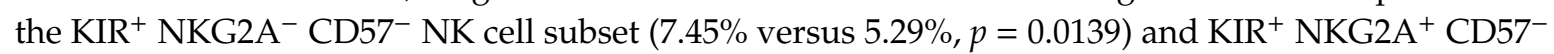


( $4.99 \%$ versus $3.29, p=0.0198$ ) (Figure 4E). These results suggest a functional advantage of $\mathrm{KIR}^{+} \mathrm{NK}$ cells against the KG1 cell line, even though they did not constitute the best effectors.
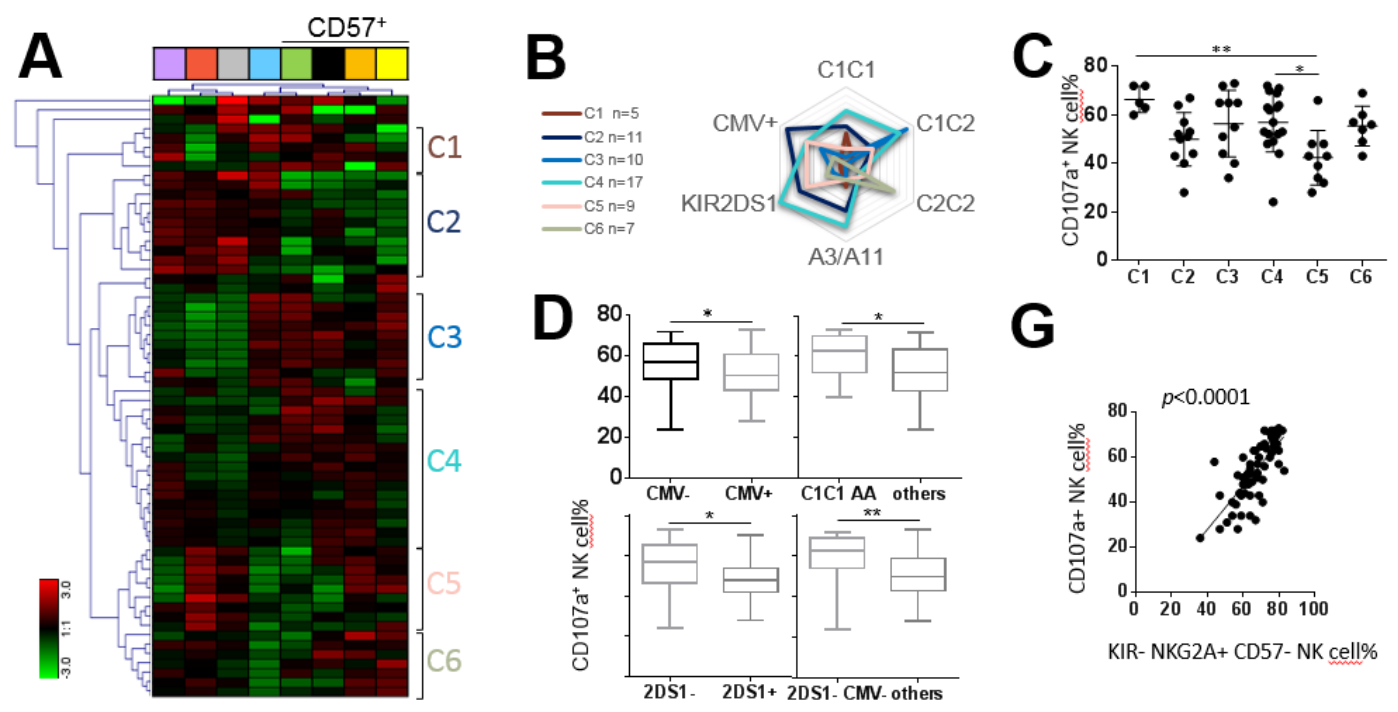

\section{$\mathbf{G}$}
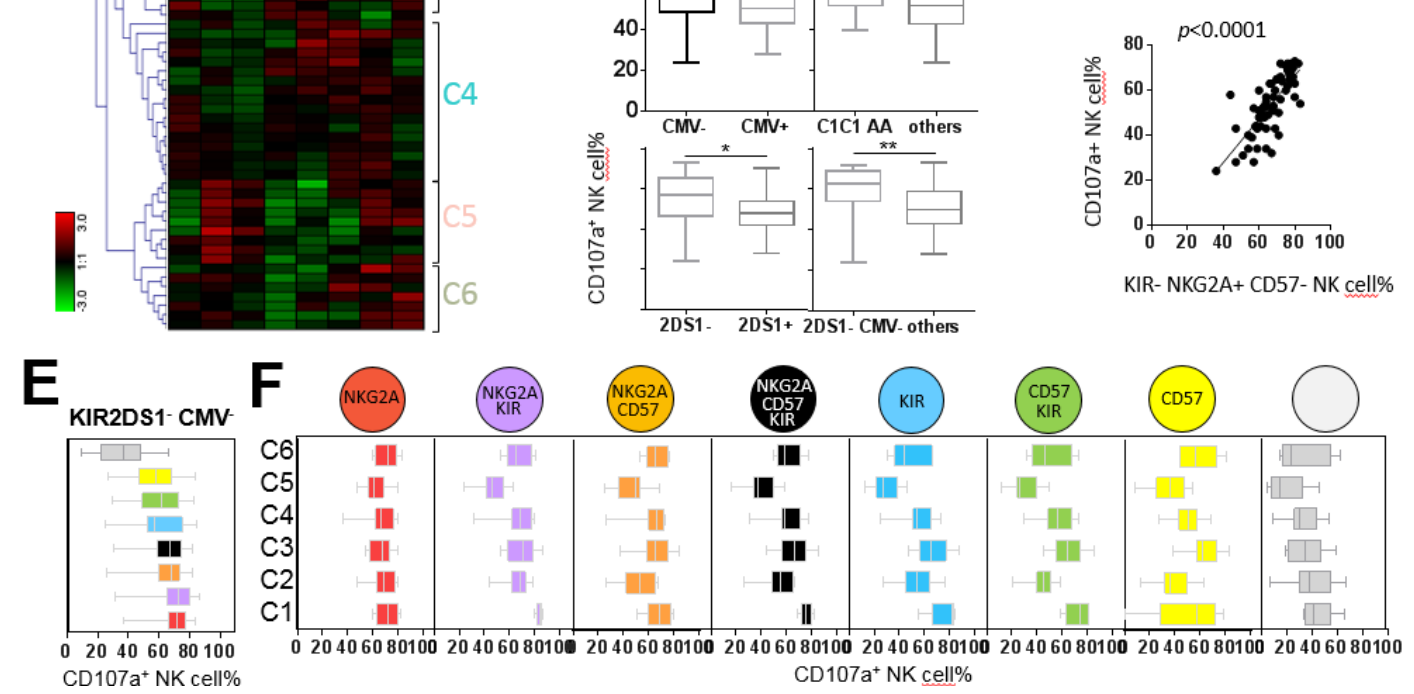

Figure 3. $\mathrm{NKG}_{2} \mathrm{~A}^{+} \mathrm{NK}$ cell subsets are the most efficient against the H9 ALL cell line. (A) Heatmap $\left(\right.$ Genesis $\left.{ }^{\circledR}\right)$ clustering of healthy blood donors $(n=68)$ from the degranulation of eight targeted NK cell subsets. NK cell subset degranulation was assessed after $5 \mathrm{~h}$ incubation in the presence of the H9 ALL cell line at an effector/target ratio of 1:1. Each column is dedicated to a defined NK cell subset. Red and green indicate high frequency and low frequency of NK cell degranulation, respectively. C1-C6 indicate the six clusters of individuals. (B) Radar charts indicating the number of blood donors for each characteristic (KIR AA or B ${ }^{+}$genotype, A3/A11, Bw4, C1 and C2 environment and CMV status) per cluster. (C) Whisker graphs of whole NK cell degranulation in each cluster. (D) Whisker graphs of whole NK cell degranulation according to $\mathrm{C} 1 \mathrm{C} 1$ environment, KIR genotype (AA), KIR gene content $\left(2 \mathrm{DS1}^{+}\right.$or $\left.2 \mathrm{DS1}^{-}\right)$and $\mathrm{CMV}$ status $\left(\mathrm{CMV}^{+}\right.$or $\left.\mathrm{CMV}^{-}\right)$investigated in 68 individuals. (E) Whisker graphs illustrating the degranulation of the eight investigated NK cell subsets from the best responders, $\mathrm{KIR}_{2} \mathrm{DS} 1^{-} \mathrm{CMV}^{-}$, against the H9 ALL cell line. NK cell subsets are classified from the highest to the lowest efficiency. NKG2A ${ }^{+} \mathrm{KIR}^{-} \mathrm{CD} 57^{-} \mathrm{NK}$ cells represented the most efficient NK cell subset against the H9 ALL cell line. (F) Whisker graphs of NK cell degranulation for each investigated NK cell subset for all clusters. (G) Correlation between $\mathrm{NKG}^{2} \mathrm{~A}^{+} \mathrm{KIR}^{-} \mathrm{CD} 57^{-} \mathrm{NK}$ cell frequencies and whole NK cell degranulation percentage from 68 individuals. $p$-values are indicated only where a significant $p$-value was obtained $(p<0.05)$. * Indicates $p<0.05,{ }^{* *}$ indicates $p<0.01$. Spearman's rank correlation coefficients were calculated, and $p$-values of $p<0.0001$ were obtained. 

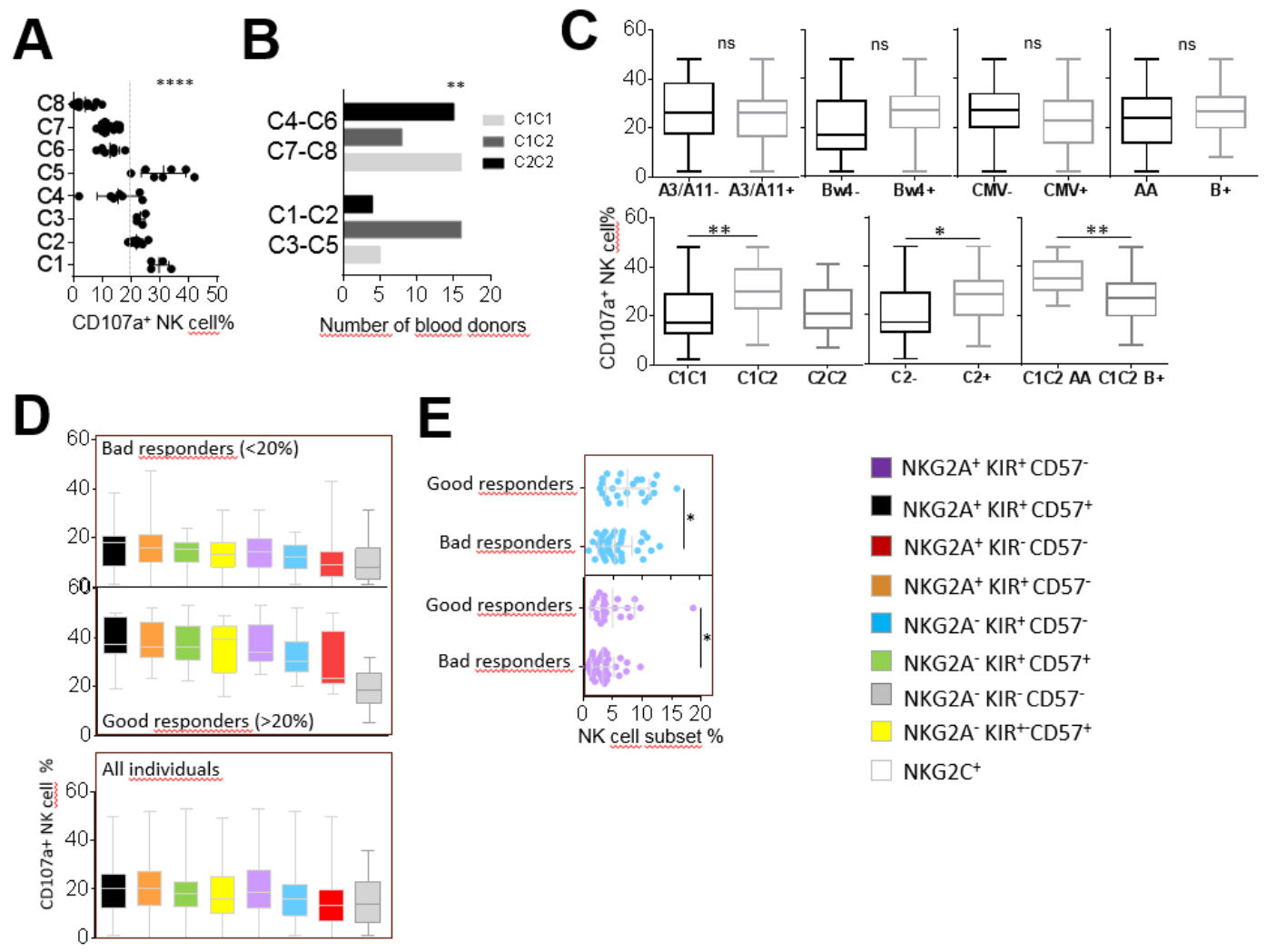

Figure 4. $\mathrm{CD}^{+} 7^{+} \mathrm{NK}$ cell subsets are the most efficient against the KG1 AML cell line. (A) Dot plots illustrating the whole NK cell degranulation of eight clusters of individuals. (B) Histograms indicating the number of individuals according to HLA-C environment $(\mathrm{C} 1 \mathrm{C} 1, \mathrm{C} 1 \mathrm{C} 2$ and $\mathrm{C} 2 \mathrm{C} 2)$ for good $(\mathrm{C} 1, \mathrm{C} 2$, $\mathrm{C} 3$ and $\mathrm{C} 5)$ and bad $(\mathrm{C} 4, \mathrm{C} 6, \mathrm{C} 7$ and $\mathrm{C} 8)$ responders. (C) Whisker graphs representing whole NK cell degranulation according to A3/A11, Bw4, C1, C2 environments, KIR genotype (AA or B+) and CMV status investigated in 68 individuals. (D) Whisker graphs illustrating the degranulation frequency of eight NK cell subsets against the KG1 AML cell line from bad and good responders and from all individuals $(n=68)$. NK cell subsets are classified from the highest to the lowest efficiency. (E) Dot plots illustrating the NK cell frequency of NKG2A ${ }^{+} \mathrm{KIR}^{-} \mathrm{CD} 57^{-}$(blue) and $\mathrm{NKG}^{2} \mathrm{~A}^{+} \mathrm{KIR}^{+} \mathrm{CD} 57^{-}$ (purple) NK cell subsets for bad and good responders. $p$-values are indicated only where a significant $p$-value was obtained $(p<0.05)$. ${ }^{*}$ Indicates $p<0.05,{ }^{* *}$ indicates $p<0.01,{ }^{* * * *}$ indicates $p<0.0001$.

Moreover, hierarchical clustering analysis of the degranulation of the eight NK cell subsets against two AML blasts (WAL-C and JAI-S) led us to identify seven clusters of individuals, as illustrated for the most representative AML blasts (WAL-C) in Figure 5A. The comparison of whole NK cell degranulation against primary AML blasts among these seven clusters revealed bad $(C 2, C 5, C 6, C 7)$ and good $(\mathrm{C} 1, \mathrm{C} 3, \mathrm{C} 4)$ responders (Figure $5 \mathrm{~B})$. The analysis of the immunogenic KIR/HLA profile of bad and good responders indicated that the best responders were significantly more likely to be $\mathrm{A} 3 / \mathrm{A} 11^{+} \mathrm{C}^{+} \mathrm{CMV}^{-}$than their bad counterparts $(p=0.024)$ (Figure $5 \mathrm{C}$ ). These results were confirmed for all individuals $(6.62 \%$ versus $3.92 \%, p=0.033)$ (Figure 5D). The most effective NK cell subsets against primary AML cells expressed KIR (Figure 5E). NKG2A ${ }^{+} \mathrm{CD} 57^{+/-} \mathrm{KIR}^{+}$cell subsets constituted the main effective NK cells against primary AML targets, in accordance with results observed against the AML KG1 cell line. Efficient NK cell subsets against AML targets were not well represented in the NK cell repertoire, explaining the low degranulation of whole NK cells observed against AML.

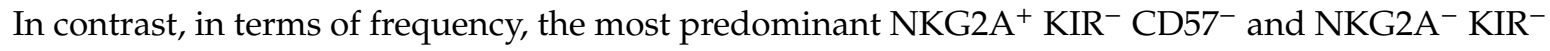
$\mathrm{CD}^{-} 7^{-} \mathrm{NK}$ cell subsets harbored very low degranulation against AML cells (Figure 5E). 

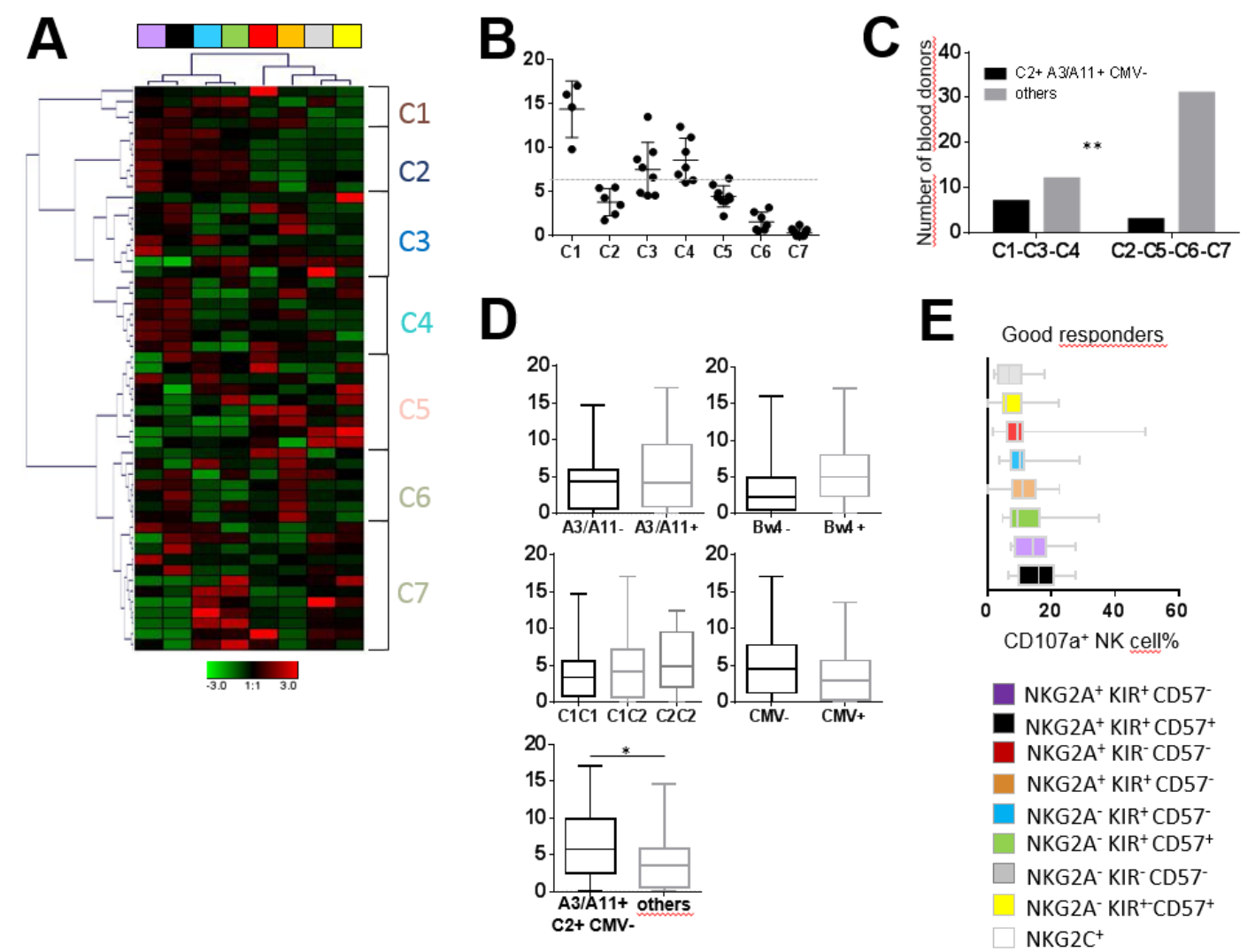

Figure 5. $\mathrm{KIR}^{+} \mathrm{NK}$ cell subsets are the most efficient against primary AML blasts. (A) Heatmap $\left(\right.$ Genesis ${ }^{\circledR}$ ) clustering of healthy blood donors $(n=51)$ from the degranulation of eight targeted NK cell subsets. NK cell subset degranulation was assessed after $5 \mathrm{~h}$ incubation in the presence of primary AML target cells at an effector/target ratio of 1:1. Each column is dedicated to a defined NK cell subset. Red and green indicate high frequency and low frequency of NK cell degranulation, respectively. C1-C7 indicate the seven clusters of individuals. (B) Dot plots illustrating whole NK cell degranulation of blood donors clustered from $\mathrm{C} 1$ to $\mathrm{C} 7$. (C) Histograms illustrating the number of individuals according to A3/A11, C2 environment and CMV for bad (C2, C5, C6 and C7) and good (C1, C3 and C4) responders. (D) Whisker graphs of whole NK cell degranulation according to HLA-Bw4, A3/A11, C1 and C2 environments and CMV status in 51 individuals. (E) Whisker graphs of the degranulation frequency of the eight investigated NK cell subsets against primary AML target cells for the good (C1, C3 and C4) responders. NK cell subsets are classified from the highest to the lowest efficiency. $p$-values are indicated only where a significant $p$-value was obtained $(p<0.05)$. ${ }^{*}$ Indicates $p<0.05$, ${ }^{* *}$ indicates $p<0.01$.

\subsection{Hyporesponsiveness of CMV-Driven NKG2C $C^{+} \mathrm{NK}$ Cell Subsets against Leukemia Target Cells}

For the study of $\mathrm{NG}_{2} \mathrm{C}^{+} \mathrm{NK}$ cell functionality, we focused only on $\mathrm{CMV}^{+}$individuals with the amplification of $\mathrm{NKG}_{2} \mathrm{C}^{+} \mathrm{NK}$ cells (higher than $12.28 \%$, corresponding to the mean value). From the 68 healthy blood donors investigated in this study, 32 individuals were CMV seropositive, and only $8 \mathrm{CMV}^{+}$individuals presented an amplification of $\mathrm{NKG}_{2} \mathrm{C}^{+} \mathrm{NK}$ cell subsets (Figure $6 \mathrm{~A}$ ). From these eight $\mathrm{CMV}^{+}$individuals, two clusters of individuals were defined by hierarchical clustering analysis of the frequency of four NKG2C ${ }^{+}$NK cell subsets based on NKG2A, KIR and CD57 marker expression (Figure $6 \mathrm{~B}, \mathrm{C}$ ). The first cluster harbored $\mathrm{C} 1^{+}$individuals (three $\mathrm{C} 1 \mathrm{C} 1$ individuals and one $\mathrm{C} 1 \mathrm{C} 2$ individual) with an amplification of the NKG2C ${ }^{+}$KIR2DL2/3 ${ }^{+}$CD57 $7^{+-}$NK cell subsets (Figure $6 \mathrm{C}$ ). In contrast, the second cluster harbored $\mathrm{C}_{2}{ }^{+}$individuals (three $\mathrm{C} 2 \mathrm{C} 2$ individuals and one $\mathrm{C} 1 \mathrm{C} 2$ individual) with an amplification of the NKG2C ${ }^{+}$KIR2DL2/3 ${ }^{-}$CD57 ${ }^{+/}$NK cell subsets (Figure 6C), in accordance with the preferential amplification of educated NK cells via inhibitory KIR [23]. 

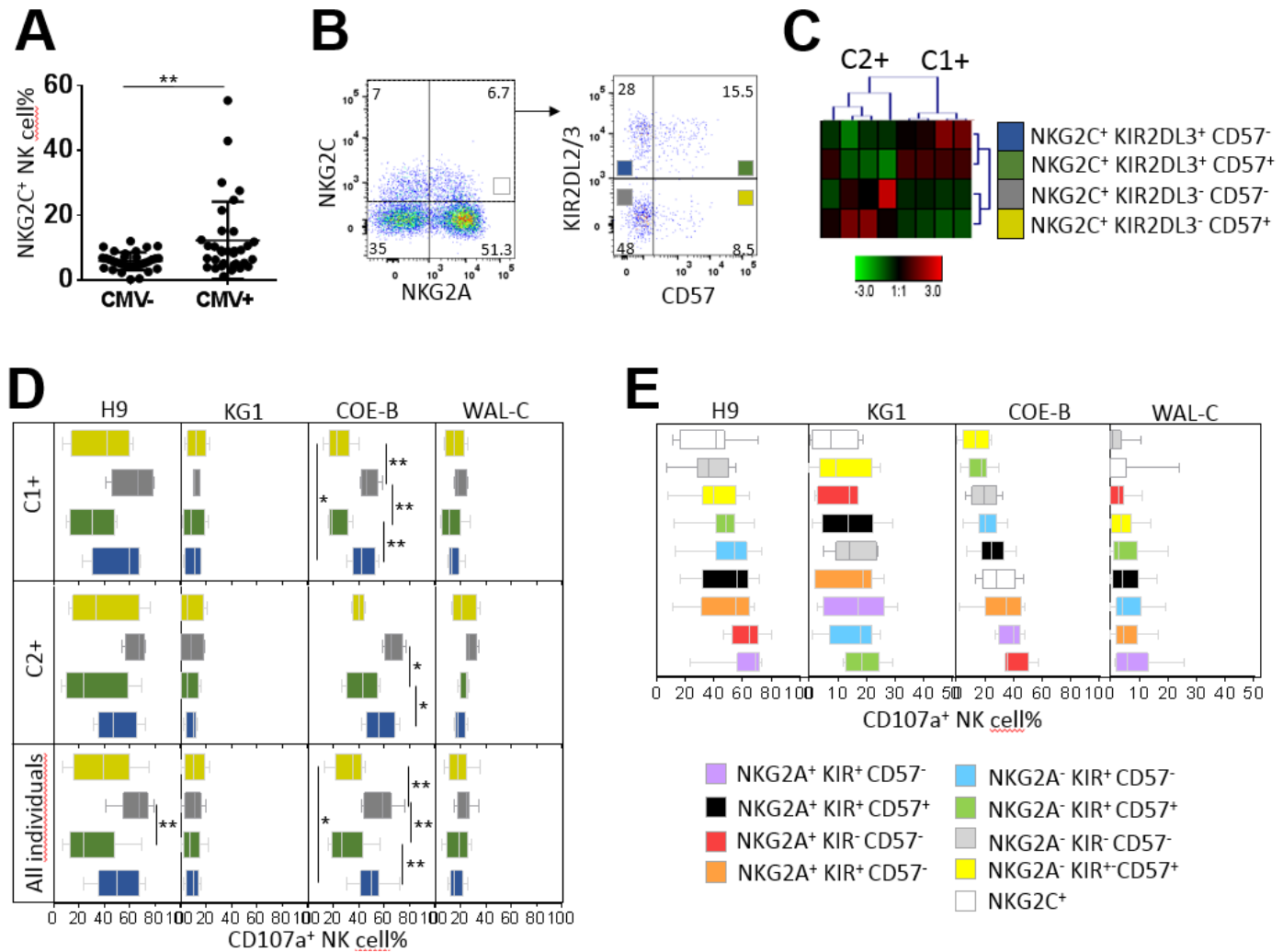

Figure 6. Degranulation potential of $\mathrm{CMV}$-driven $\mathrm{NKG}_{2} \mathrm{C}^{+} \mathrm{NK}$ cell subsets against leukemia target cells. (A) Dot plots of NKG2 $\mathrm{C}^{+} \mathrm{NK}$ cell frequencies in $\mathrm{CMV}^{-}(\mathrm{n}=32)$ and $\mathrm{CMV}^{+}(\mathrm{n}=36)$ individuals. (B) Density plots illustrating the cell strategy to target NKG2C + NK cell subsets expressing or not expressing KIR2DL2/3 and CD57. (C) Heatmap (Genesis ${ }^{\circledR}$ ) clustering of $\mathrm{CMV}^{+}$blood donors with NKG2C NK cell amplification $(\mathrm{n}=8)$ from the frequencies of the four $\mathrm{NKG}_{2} \mathrm{C}^{+}\left(\mathrm{KIR}^{+} \mathrm{CD} 57^{+}, \mathrm{KIR}^{+} \mathrm{CD} 57^{-}, \mathrm{KIR}^{-} \mathrm{CD} 57^{+}\right.$ and $\mathrm{KIR}^{-} \mathrm{CD}^{-} 7^{-}$) $\mathrm{NK}$ cell subsets. Each column is dedicated to a defined NK cell subset. The color of each square reflects the percentage of the corresponding subset. Red and green indicate high and low frequencies of NK cell subsets, respectively. (D) Whisker graphs of the degranulation of the four $\mathrm{NKG}_{2} \mathrm{C}^{+} \mathrm{NK}$ cell subsets against ALL H9 and AML KG1 cell lines, primary ALL COE-B and AML WAL-C blasts for $\mathrm{C}^{+}(\mathrm{n}=4), \mathrm{C}^{+}(\mathrm{n}=4)$ and all individuals $(\mathrm{n}=8)$. (E) Whisker graphs of degranulation frequency of the nine investigated $\mathrm{NK}$ cell subsets from $\mathrm{CMV}^{+}$individuals $(\mathrm{n}=9)$ with amplification of the $\mathrm{NKG}_{2} \mathrm{C}^{+} \mathrm{NK}$ cell subsets against $\mathrm{H9}$, KG1, CO-E and WAL-C. NK cell subsets are classified from the highest to the lowest efficiency. $p$-values are indicated only where a significant $p$-value was obtained $(p<0.05)$. ${ }^{*}$ Indicates $p<0.05$ and ${ }^{* *}$ indicates $p<0.01$.

The degranulation of $\mathrm{NKG}^{+} \mathrm{C}^{+} \mathrm{KIR} 2 \mathrm{DL} 2 / 3^{-} \mathrm{CD}^{-} 7^{-} \mathrm{NK}$ cell subsets against ALL cells (H9 cell line and primary ALL blasts) was significantly higher than that of $\mathrm{NKG}_{2} \mathrm{C}^{+} \mathrm{KIR} 2 \mathrm{DL} 2 / 3^{+} \mathrm{CD} 57^{+} \mathrm{NK}$ cell subsets $(64.46 \%$ versus $30.75 \%, p=0.0084$, against $\mathrm{H} 9$, and $56.53 \%$ versus $31.87 \%, p=0.0011$, for COE-B blasts), regardless of the HLA-C environment of NK cells $\left(\mathrm{C}^{+}{ }^{+}\right.$or $\left.\mathrm{C}^{+}\right)$(Figure 6D). Of note, the $\mathrm{C}^{+} \mathrm{NK}$ responses of all NK cell subsets against ALL blasts were higher than the $\mathrm{C}^{+}$counterpart, in accordance with our previous results obtained from the whole cohort. In contrast, the degranulation of all NKG2C $\mathrm{C}^{+} \mathrm{NK}$ subsets was low against the AML KG1 cell line and blasts. Overall, we observed that $\mathrm{NKG}_{2 \mathrm{C}^{+}} \mathrm{KIR} 2 \mathrm{DL} 2 / 3^{-} \mathrm{CD} 57^{-} \mathrm{NK}$ cell subsets (and probably KIR2DL1 ${ }^{+}$), amplified in $\mathrm{C}^{+} \mathrm{CMV}^{+}$ individuals, were the most effective subsets against ALL H9 and primary cells, as well as against primary AML targets.

Several research groups consider memory-like $\mathrm{NKG}_{2} \mathrm{C}^{+} \mathrm{NK}$ cells to be attractive anti-leukemia candidates for immunotherapy [25]. Thus, we further examined the degranulation potential of memory-like $\mathrm{NKG}_{2} \mathrm{C}^{+} \mathrm{NK}$ cells in these eight $\mathrm{CMV}^{+}$individuals. We compared that to the 
degranulation of eight NK cell subsets defined on the basis of NKG2A, KIR and CD57 markers. The degranulation of $\mathrm{NKG}_{2} \mathrm{C}^{+} \mathrm{NK}$ cells was low against $\mathrm{H9}$, KG1 and primary AML blasts (Figure 6E). Although the whole $\mathrm{NKG}_{2} \mathrm{C}^{+} \mathrm{NK}$ cell population exhibited better responses against primary ALL blasts (Figure 6E), this population seems to be not as attractive for harnessing anti-leukemia immunity.

\section{Discussion}

On the basis of clinical data, NK cells appear to play a crucial role in the eradication of acute leukemia [26-28]. However, the ability of NK cells to mediate a response against tumor cells such as leukemia cells depends on the presence of ligands that are recognized by NK receptors on tumor cells $[12,13,26,29]$. In this study, a broad diversity of NK cell responses was observed in vitro against myeloid and lymphoid cell lines. Most of the lymphoid cell lines triggered stronger NK cell responses than myeloid cell lines. Furthermore, a broad inter-individual disparity of NK cell responses was observed against the same leukemic target, highlighting bad and good NK responders. In addition, the best responders against one target were not systematically good responders against another. These results showed that the diversity of NK cell responses against leukemic cells were inter- and intra-individual. On the basis of NKG2A, KIR2DL2/3, CD57 and NKG2C markers, we determined different clusters of individuals who shared a common NK cell repertoire linked to the immunogenetic KIR/HLA profile and CMV status. We found that the NKG2A ${ }^{+}$KIR2DL2/3- CD57- NK cell subset was predominantly represented in the majority of $\mathrm{NK}$ cell repertoires and more significantly in $\mathrm{C} 2 \mathrm{C} 2 \mathrm{Bw} 4^{+}$ genotyped individuals. Of note, $\mathrm{C} 2 \mathrm{C} 2$ individuals are more represented in the African population (up to $40 \%$ ) than Caucasian (20\%) and Asian (less than 5\%) populations. HLA-C of the C2 group and HLA-Bw4 ligands contribute to the education and maturation of KIR2DL1 and KIR3DL1 NK cells, respectively [4]. As KIR2DL1 and KIR3DL1 expression were not investigated in this study, it is possible that a proportion of NKG2A ${ }^{+}$KIR2DL2/3- CD57 ${ }^{-}$NK cells express KIR2DL1 and KIR3DL1

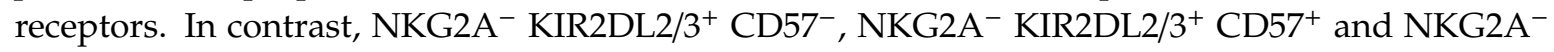
KIR2DL2/3- $\mathrm{CD}^{-} 7^{+} \mathrm{NK}$ cell subsets were represented in low frequencies in NK cell repertoires.

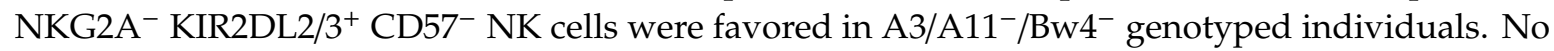
significant difference between $\mathrm{C} 1$ and $\mathrm{C} 2$ ligands was observed in the frequency of this KIR2DL2/3 ${ }^{+}$ NK cell subset. Thus, the absence of $\mathrm{A} 3 / \mathrm{A} 11$ and $\mathrm{Bw} 4$ ligands suggests that $\mathrm{C} 1$ or $\mathrm{C} 2$ ligands favored the education and development of the NKG2A- KIR2DL2/3+ ${ }^{+} \mathrm{CD}^{-} 7^{-} \mathrm{NK}$ cell subset since it has been reported that the KIR2DL3 receptor can strongly recognize the $\mathrm{C} 1$ ligand and recognizes the $\mathrm{C} 2$ ligand with low affinity [30]. NKG2A- KIR2DL2/3 ${ }^{+} \mathrm{CD} 57^{+}$and NKG2A ${ }^{-} \mathrm{KIR} 2 \mathrm{DL} 2 / 3^{-} \mathrm{CD} 57^{+} \mathrm{NK}$ cell subsets were particularly favored in A3/A11 ${ }^{+}$genotyped individuals. As A3/A11 HLA class I molecules, originally identified as ligands for the KIR3DL2 inhibitory receptor [31], participate in the development of KIR3DL2 ${ }^{+} \mathrm{NK}$ cells, we can speculate that a proportion of $\mathrm{NKG}^{-\mathrm{A}^{-} \mathrm{CD} 57^{+}} \mathrm{NK}$ cells express KIR3DL2. Our data are placed in a broad body of literature on the structuration of the NK cell repertoire [30,32-37], with the notably recent study of Pfefferle et al., showing a well-maintained NK cell repertoire over time [18]. Indeed, the intra-lineage plasticity maintains phenotypic and functional NK cell homeostasis, and the acquired phenotype determines functional potential in NK cells. Because the KIR2DL2 $/ 3^{+}$NK cell represents the most prevalent NK cell subset in the KIR NK cell repertoire, we focused only on the KIR2DL2/3 inhibitory receptor in this study. However, further investigations are needed to evaluate the role of other inhibitory KIR receptors, such as KIR2DL1, KIR3DL1 and KIR3DL2, in anti-leukemia NK cell responses, particularly against AML.

An in-depth functional analysis identified NKG2A ${ }^{+} \mathrm{KIR}^{-} \mathrm{CD} 57^{-} \mathrm{NK}$ cells as the most effective NK cell subsets against the ALL H9 cell line and ALL blasts, as previously reported [38]. The fact that $\mathrm{NKG}_{2} \mathrm{~A}^{+} \mathrm{NK}$ cells were represented at a high frequency in the NK cell repertoire explains the strong response of these subsets against ALL targets. Moreover, Forslun et al. reported that NKG2A ${ }^{+}$ $\mathrm{KIR}^{-} \mathrm{CD}^{-} 7^{-}$NK cells exhibit more dynamic migration, which is associated with increased target cell conjugation and a higher probability of killing compared with $\mathrm{NKG}^{2} \mathrm{~A}^{-} \mathrm{KIR}^{-} \mathrm{CD} 57^{-} \mathrm{NK}^{-}$cells. The authors suggested that the ability of $\mathrm{NKG}_{2} \mathrm{~A}^{+} \mathrm{NK}$ cells to form more conjugates resulted in 
their increased motility, leading to more encounters with target cells [39]. In our study, ALL targets expressed HLA-E molecules. We can speculate that this inhibitory effect of NKG2A is probably counterbalanced by the strong activating signals mediated through the interaction of NKG2D and DNAM-1 and their cognate ligands expressed on ALL targets. Thus, the cellular mechanism behind the efficient response mediated by these NK cells expressing NKG2A, particularly the response against lymphoid cells, remains unclear. Of note, good responders against ALL targets were either KIR2DS1or $\mathrm{C} 2 \mathrm{C} 2$ individuals, the latter harboring a higher frequency of $\mathrm{NKG}^{+} \mathrm{A}^{+} \mathrm{KIR}^{-} \mathrm{CD} 57^{-} \mathrm{NK}$ cells. These parameters are important, as they can help in choosing donors of HSC that harbor more efficient and abundant NKG2A ${ }^{+} \mathrm{KIR}^{-} \mathrm{CD} 57^{-} \mathrm{NK}$ cells to treat acute lymphoblastic leukemia.

In the context of haploidentical HSCT, numerous studies have reported that NK cell-mediated alloreactivity is induced by donor $\mathrm{KIR}^{+} \mathrm{NK}$ cells [40-42]. In a previous study, we documented that KIR/HLA incompatibilities were associated with the more differentiated phenotype of the NK cell repertoire at the time of GvHD, limiting the incidence of relapse after haploidentical HSCT [14]. In line with these previous studies, we report here that more differentiated NK cells expressing KIR and CD57 markers were the most effective NK cells against AML targets, including primary AML blasts. Although $\mathrm{KIR}^{+}$and $\mathrm{CD} 57^{+}$NK cells represented the most effective NK cells against AML targets, the low frequency of these NK cell subsets explains why AML targets did not trigger whole NK cell degranulation. Conversely, NKG2A ${ }^{+} \mathrm{KIR}^{-} \mathrm{CD} 57^{-} \mathrm{NK}$ cells harbor a low responsiveness against AML targets. This observation is in line with the study of Nguyen et al., who showed that increased frequency of immature $\mathrm{NKG}_{2} \mathrm{~A}^{+} \mathrm{NK}$ cells during NK cell repertoire reconstitution after HSCT did not produce a GvL effect in AML patients [43]. In contrast, $\mathrm{KIR}^{+} \mathrm{NK}$ cells with the CD57 phenotype display increased functional potential associated with the increased transcription of genes involved in adhesion and immune synapse [18]. Altogether, these data suggest that $\mathrm{KIR}^{+}$and $\mathrm{CD} 57^{+} \mathrm{NK}$ cell subsets may be more adapted to interact with and eliminate AML target cells. Among different therapeutic approaches developed to enhance NK cell cytotoxicity against cancer [44], the expansion of allogeneic NK cells constitutes an appealing approach [45]. Thus, the expansion of selected NK cells based on KIR and CD57 expression should constitute promising cell immunotherapy after HSCT to improve the GvL effect in AML patients. Moreover, new insights open avenues in NK cell-based immunotherapy, in particular, chimeric activating receptor (CAR) NK cells [46]. We can imagine genetically engineering the most efficient $\mathrm{KIR}^{+}$and $\mathrm{CD} 57^{+} \mathrm{NK}$ cell subsets against AML to harness their ability to kill these targets.

Furthermore, we documented the massive amplification of adaptive and more differentiated $\mathrm{NKG}_{2} \mathrm{C}^{+} \mathrm{NK}$ cells in seropositive CMV individuals, consistent with previous reports [20-23]. $\mathrm{NKG}_{2} \mathrm{C}^{+} \mathrm{KIR}_{2} \mathrm{DL} 3^{+} \mathrm{CD} 57^{+/-}$cells were preferentially expanded in $\mathrm{C}^{+}$individuals, whereas $\mathrm{NKG}^{+} \mathrm{C}^{+}$ KIR2DL3 ${ }^{-}$CD57 $7^{+-}$NK cells were preferentially expanded in $\mathrm{C}^{+}$individuals, demonstrating the important role of the HLA-C environment in the expansion of such NK cell subsets, as previously observed [20,23,47,48]. Lopez-Vergès et al., reported that during CMV infection, there is a unique expansion of $\mathrm{NKG}_{2} \mathrm{C}^{+} \mathrm{CD} 57^{+} \mathrm{NK}$ cells, and they proposed that $\mathrm{CD} 57$ might provide a marker of "memory" NK cells in response to CMV infection [49]. Our study identified expanded NKG2C ${ }^{+}$ NK cells with and without CD57 expression, suggesting the presence of phenotypic intra-individual diversity of the $\mathrm{NKG}_{2} \mathrm{C}^{+} \mathrm{NK}$ cell repertoire in CMV seropositive individuals. Functionally, adaptive $\mathrm{NKG}_{2} \mathrm{C}^{+} \mathrm{NK}$ cell responses were more diverse than initially expected [40]. Interestingly, we noted low responsiveness of the well-described adaptive and memory-like $\mathrm{NKG}_{2} \mathrm{C}^{+} \mathrm{KIR}^{+} \mathrm{CD} 57^{+} \mathrm{NK}$ cells against all leukemia targets, in contrast to other $\mathrm{NKG}_{2} \mathrm{C}^{+} \mathrm{NK}$ cell subsets. Our study identified $\mathrm{NKG}_{2} \mathrm{C}^{+}$ $\mathrm{KIR}^{-} \mathrm{CD} 57^{-} \mathrm{NK}$ cells as the most effective $\mathrm{NKG}^{-} \mathrm{C}^{+} \mathrm{NK}$ cell subset. Of note, taking into account all NK cell subsets investigated on the basis of KIR, CD57 and NKG2A expression, the $\mathrm{NKG}_{2} \mathrm{C}^{+} \mathrm{NK}$ cell subset was among the least efficient NK cell subset against all leukemia targets. Merino et al. recently showed that chronically stimulated adaptive NK cells were dysfunctional when challenged with tumor cells [50]. Although this NK subset displays attractive characteristics, we observed limited anti-tumor efficiency. 
In conclusion, our data may have evident clinical implications, as they can be used to optimize the selection of HSC donors on the basis of immunogenetic KIR and HLA for ALL patients and identify the best NK cell subsets in immunotherapy to cure AML patients.

\section{Materials and Methods}

\subsection{Peripheral Blood Mononuclear Cells (PBMCs), Cell Lines and Primary Target Cells}

Peripheral blood mononuclear cells (PBMCs) were isolated as previously described [32]. All blood donors were recruited at the Blood Transfusion Center (EFS, Nantes, France), and informed consent was given by all donors. A panel of myeloid and lymphoid cell lines $(n=10)$ and primary leukemic cells $(n=2)$ were used to investigate the potential of NK cell degranulation. Cell lines included acute myeloid leukemia (AML) cell lines ( $\mathrm{n}=4)$ : HL60, KG1, NB-4 and OCI-AML3; T-acute lymphoblastic leukemia (T-ALL) cell lines ( $n=4)$ : Jurkat, Molt-4, HP B-ALL and H9; and Burkitt Lymphoma cell lines ( $n=2)$ : Raji and Daudi. KG1, NB4 and OCI-AML3 cell lines were generously supplied by Dr Nicolas Dulphy (UMRS-1160 INSERM, Paris, France). Cell lines were cultured in RPMI 1640 medium (Gibco, Paisley, Scotland, UK) containing glutamine (Gibco) and penicillin-streptomycin (Gibco) and supplemented with 10\% fetal bovine serum (Gibco). Mycoplasma tests performed by PCR were negative for all cell lines. Blood samples from two patients with acute leukemia were used to isolate leukemic blasts by the same method used for PBMC isolation. All patients gave their informed consent to physicians from the clinical hematology department of the Nantes University Hospital (Pr. Patrice Chevallier). Primary leukemic cells included one acute myeloid leukemia (AML) target (blasts $>90 \%$ ) and one B-acute lymphoblastic leukemia (B-ALL) target (blasts > 95\%) named WAL-C and COE-B, respectively. All leukemic cells (lines and blasts) were HLA typed. A declaration of preparation and conservation of these biocollections (DC-2014-2340) has been provided to French Research Minister and has received approval from the IRB (2015-DC-1).

\subsection{HLA and KIR Genotyping}

HLA class I allele assignment and KIR gene content typing were performed as previously described [14] for all volunteer blood donors $(n=68)$. KIR genetic typing was performed on all donor samples using a KIR multiplex PCR-SSP method as previously described using specific KIR primers provided by Dr. Ketevan Gendzekhadze (City of Hope, Duarte, CA, USA) [51]. More details are provided in Appendix A.

\subsection{HCMV Serology}

CMV serology was carried out by the technical platform of the Virology Department of Nantes University Hospital (Pr. Berthe-Marie Imbert and Dr. Céline Bressollette) using plasmas from donor biocollections. The CMV serological status of donors was determined by the detection of IgG2 anti-CMV antibodies in plasmas using the LIAISON chemiluminescent immune test (DiaSorin, Saluggia, Italie) according to the manufacturer's instructions [23]. Our cohort of blood donors comprised 35 seronegative $\mathrm{CMV}$ individuals $\left(\mathrm{CMV}^{-}\right)$and 33 seropositive $\mathrm{CMV}$ individuals $\left(\mathrm{CMV}^{+}\right)$.

\subsection{Phenotypic Analysis of NK Cells, Cell Lines and Primary Leukemic Cells by Flow Cytometry}

High-resolution immunophenotyping of NK cells, cell lines and primary leukemic cells was determined by eight-color multiparameter flow cytometry (MFC) using the mouse anti-human mAbs presented in Appendix A.

\subsection{CD107a Mobilization Assay Detected by Flow Cytometry}

NK cells from healthy blood donors were pre-incubated with anti-CD107a-BV421 (H4A3, BD Biosciences, Le Pont de Claix, France). CD107a is a sensitive marker for the identification of NK cell activity [52] and can be used for isolation of tumor-cytolytic cells [53]. NK cell degranulation 
against myeloid and lymphoid cell lines was assessed after incubation for $5 \mathrm{~h}$ alone (negative control) or with different target cells (E/T ratio $=1: 1$ and $2.5 \times 10^{6}$ cells/well) in bottom 96 well plate with brefeldin A (Sigma, Lezennes, France) at $10 \mu \mathrm{g} / \mathrm{mL}$ for the last $4 \mathrm{~h}$. An initial cell surface staining was used to target NK cell subsets by MFC using the following mouse-Abs combination: CD57-FITC, NKG2C-PE, NKG2D-PerCP-Cy5.5, NKG2A-PC7, KIR2DL2/3-APC, CD56-APC-Cy7 and CD3-BV510. A second cell surface staining was used to analyze NK cell activating receptor expression by MFC using the following mouse-Abs combination: 2B4-FITC, NKp30-PE, DNAM-1-PerCP-Cy5.5, NKp44-PC7 and NKp46-APC. As some primary leukemic cells expressed CD56, the NKp46 marker was used to target NK cells in the degranulation assay by MFC using the following mouse-Abs combination: NKG2A-FITC, NKG2C-PE, KIR2DL2/3-PE-Cy5.5, CD57-PC7, KIR2DL2/3-APC and NKp46-APC. All flow cytometry data were collected using a FACSCanto II (BD Biosciences) and analyzed with Flowjo ${ }^{\mathrm{TM}} 10.6$ software (BD Biosciences).

\subsection{Hierarchical Clustering Analysis of NK Cell Phenotype and Degranulation}

The hierarchical clustering of investigated NK cell subsets was performed following a complete linkage using the Genesis software [54]. The software is available at www.genome.tugraz.at.

\subsection{Statistical Analyses}

Comparisons of NK cell frequencies between two different series of individuals were performed by Student's $t$-test. Comparisons of multiple groups were performed by one-way ANOVA using the GraphPad Prism v6.0 software (Ritme informatique, Paris, France). $p$-values $<0.05$ were considered statistically significant.

\section{Conclusions}

In conclusion, this study showed a broad inter-individual disparity of NK cell responses against the same leukemic target, highlighting bad and good NK responders. We observed that the diversity of NK cell responses against leukemic cells was inter- and intra-individual. Indeed, on the basis of NKG2A, KIR2DL2/3, CD57 and NKG2C markers, we identified different clusters of individuals who shared a common NK cell repertoire that was linked to the immunogenetic KIR/HLA profile and CMV status. On the functional side, the most effective NK cell subsets against different ALL targets expressed NKG2A and represented the most frequent subset in the NK cell repertoire. In contrast, minority $\mathrm{CD} 57^{+}$or/and $\mathrm{KIR}^{+} \mathrm{NK}$ cell subsets were more efficient against AML. These results may have evident implications in oncohematology to improve both the selection of hematopoietic stem cell donors for ALL patients and immunotherapies to cure AML patients.

Supplementary Materials: The following are available online at http://www.mdpi.com/2072-6694/12/7/1927/s1, Figure S1: Immunophenotyping of H9 ALL and KG1 AML cell lines; Figure S2: Flow cytometry strategy to determine the frequency of different NK cell subsets; Figure S3: NKG2A ${ }^{+}$NK cell subsets are the most efficient against primary ALL blasts.

Author Contributions: Study design: C.R. and B.C.; acquisition and analysis of flow cytometry data: D.R.M., F.D.R.d.L., G.D. and C.W.; Genesis analysis: C.R. and D.R.M.; HLA typing: A.C.; KIR genotyping: N.L., L.D., K.G. (Ketevan Gendzekhadze) and K.G. (Katia Gagne); patient's sample collection and clinical documentation: A.G., A.L., M.C.B., P.P., T.G. and P.C.; data interpretation: D.R.M., F.D.R.d.L. and C.R.; manuscript writing: D.R.M. and C.R.; English editing: K.G. (Ketevan Gendzekhadze). All authors have read and agreed to the published version of the manuscript.

Funding: This research was funded by the Etablissement Français du Sang (EFS)/Centre Pays de la Loire and by grants from International Research Group on unrelated hematopoietic stem cell Transplantation (IRGHET), la Ligue contre le Cancer (comité de Loire-Atlantique, comité de la Vienne, comité de la Vendée, comité du Morbihan et le comité des Deux Sèvres), DHU Oncogreffe, Leucémie Espoir Atlantique Famille (LEAF) and l'Agence de Biomédecine (ABM). DRM is a PhD student supported by Industrial Agreement for Training Through Research Grants 2017/0850. LD is a PhD student supported by La Region Pays de la Loire (2018-09766).

Acknowledgments: We thank all volunteer blood donors and patients who agreed to participate in the study.

Conflicts of Interest: The authors declare no conflict of interest. 


\section{Appendix A}

\section{A.1. HLA and KIR Genotyping}

The presence or absence of KIR2DL1, 2DL2, 2DL3, 2DL5, 3DL1, 2DS1, 2DS2, 2DS3, 2DS4/1D, 2DS5 and 3DS1 genes was established. Donor KIR genotypes were then determined on the basis of the presence or the absence of activating KIR. Thus, a KIR AA genotype was defined by the presence of only KIR2DS4 as the activating KIR gene, and a KIR B+ genotype was defined by the presence of several activating KIR genes [55]. KIR ligands such as A3/A11, Bw4, C1 and C2 were defined on the basis of allelic HLA class I typing. In this study, we included $30 \mathrm{AA}$ and $38 \mathrm{~B}+$ KIR genotyped healthy blood donors and $24 \mathrm{C} 1 \mathrm{C} 1,26 \mathrm{C} 1 \mathrm{C} 2$ and $18 \mathrm{C} 2 \mathrm{C} 2$ genotyped individuals. Among healthy blood donors, 18 individuals harbored the KIR2DS1 gene, 53 individuals were $\mathrm{Bw} 4^{+}$, and 30 individuals were $\mathrm{A} 3 / \mathrm{A}_{1} 1^{+}$genotyped.

\section{A.2. NK Cell Phenotypic Analysis by Flow Cytometry}

The NK cell surface phenotype was determined by eight-color multiparameter flow cytometry (MFC) on PBMCs using the following mouse anti-human mAbs: anti-KIR2DL2/3-APC (GL183, Beckman Coulter, Immunotech, Marseilles, France), anti-CD3-BV510 (UCHT1, BD Biosciences, San Jose, CA, USA), anti-CD56-APC-Cy7 (NCAM16.2, BD Biosciences), anti-NKp30-PE (Z25, Beckman Coulter, Bréa, CA, USA), anti-NKp44-PE-Cy7 (P44-8, Beckman Coulter), anti-NKp46-APC (9E2, BD Biosciences), anti-NKG2A-PE-Cy7 (Z199, Beckman Coulter), anti-NKG2C-PE (134591, R\&D Systems, Minneapolis, MN, USA), anti-CD57-FITC (HNK-1, BD Biosciences), anti-DNAM-1-PercP-Cy5.5 (11A8, Biolegend, San Diego, CA, USA), anti-2B4-FITC (2-69) and anti-NKG2D-PerCP-Cy5.5 (1D11, Biolegend).

\section{A.3. Phenotypic Analysis of Cell Lines and Primary Leukemic Cells by Flow Cytometry}

High-resolution immunophenotyping of cell lines and primary leukemic cells was determined by eight-color multiparameter flow cytometry (MFC) using the following mouse anti-human mAbs: anti-HLA class I-FITC (F41-IE3H1D2, EFS Nantes, France), anti-HLA-E-PE, anti-MICA/B-PE-Cy7 (6D4, Sony Biotechnology, San Jose, CA, USA), anti-ULBP-1-FITC (170818, R\&D Systems, Minneapolis, Minn, USA), anti-ULBP-2/5/6-PE (165903, R\&D Systems), anti-ULBP3-PE (166510, R\&D Systems), anti-ULBP-4-PE (709116, R\&D Systems), anti-B7-H6-APC (875001, R\&D Systems), anti-CD155 (PVR)-APC (SKII.4, Biolegend), anti-CD112 (Nectin-2)-APC (TX31, Sony), anti-PDL-1 (CD274)-PE-Cy7 (29.E2A3, Sony), anti-CD48-FITC (BJ40, Biolegend), anti-CD3-PerCP (SK7, BD Biosciences), anti-CD56-APC-Cy7 (NCAM16.2, BD Biosciences), anti-CD19-FITC (SJ25CI, BD Biosciences), anti-CD33-PerCP-Cy5.5 (WM53, Sony), anti-CD34-BV510 (581, Sony) and anti-CD45-BV421 (HI30, Sony).

\section{References}

1. Iannello, A.; Thompson, T.W.; Ardolino, M.; Marcus, A.; Raulet, D.H. Immunosurveillance and immunotherapy of tumors by innate immune cells. Curr. Opin. Immunol. 2016, 38, 52-58. [CrossRef]

2. Waggoner, S.N.; Reighard, S.D.; Gyurova, I.E.; Cranert, S.A.; Mahl, S.E.; Karmele, E.P.; McNally, J.P.; Moran, M.T.; Brooks, T.R.; Yaqoob, F.; et al. Roles of natural killer cells in antiviral immunity. Curr. Opin. Virol. 2016, 16, 15-23. [CrossRef]

3. Kärre, K. MHC gene control of the natural killer system at the level of the target and the host. Semin. Cancer Biol. 1991, 2, 295-309. [PubMed]

4. Anfossi, N.; André, P.; Guia, S.; Falk, C.S.; Roetynck, S.; Stewart, C.A.; Breso, V.; Frassati, C.; Reviron, D.; Middleton, D.; et al. Human NK cell education by inhibitory receptors for MHC class I. Immunity 2006, 25, 331-342. [CrossRef] [PubMed]

5. Boudreau, J.E.; Hsu, K.C. Natural killer cell education in human health and disease. Curr. Opin. Immunol. 2018, 50, 102-111. [CrossRef] 
6. Braud, V.M.; Allan, D.S.J.; O’Callaghan, C.A.; Söderström, K.; D’Andrea, A.; Ogg, G.S.; Lazetic, S.; Young, N.T.; Bell, J.I.; Phillips, J.H.; et al. HLA-E binds to natural killer cell receptors CD94/NKG2A, B and C. Nature 1998, 391, 795-799. [CrossRef] [PubMed]

7. Del Zotto, G.; Marcenaro, E.; Vacca, P.; Sivori, S.; Pende, D.; Della Chiesa, M.; Moretta, F.; Ingegnere, T.; Mingari, M.C.; Moretta, A.; et al. Markers and function of human NK cells in normal and pathological conditions: Markers and Function Of Human Nk Cells. Cytometry B Clin. Cytom. 2017, 92, $100-114$. [CrossRef]

8. Chiossone, L.; Vienne, M.; Kerdiles, Y.M.; Vivier, E. Natural killer cell immunotherapies against cancer: Checkpoint inhibitors and more. Semin. Immunol. 2017, 31, 55-63. [CrossRef]

9. Gaggero, S.; Bruschi, M.; Petretto, A.; Parodi, M.; Del Zotto, G.; Lavarello, C.; Prato, C.; Santucci, L.; Barbuto, A.; Bottino, C.; et al. Nidogen-1 is a novel extracellular ligand for the NKp44 activating receptor. Oncoimmunology 2018, 7, e1470730. [CrossRef]

10. Niehrs, A.; Garcia-Beltran, W.F.; Norman, P.J.; Watson, G.M.; Hölzemer, A.; Chapel, A.; Richert, L.; Pommerening-Röser, A.; Körner, C.; Ozawa, M.; et al. A subset of HLA-DP molecules serve as ligands for the natural cytotoxicity receptor NKp44. Nat. Immunol. 2019, 20, 1129-1137. [CrossRef]

11. Barrow, A.D.; Edeling, M.A.; Trifonov, V.; Luo, J.; Goyal, P.; Bohl, B.; Bando, J.K.; Kim, A.H.; Walker, J.; Andahazy, M.; et al. Natural Killer Cells Control Tumor Growth by Sensing a Growth Factor. Cell 2018, 172, 534-548. [CrossRef] [PubMed]

12. Mastaglio, S.; Wong, E.; Perera, T.; Ripley, J.; Blombery, P.; Smyth, M.J.; Koldej, R.; Ritchie, D. Natural killer receptor ligand expression on acute myeloid leukemia impacts survival and relapse after chemotherapy. Blood Adv. 2018, 2, 335-346. [CrossRef] [PubMed]

13. Pende, D.; Spaggiari, G.M.; Marcenaro, S.; Martini, S.; Rivera, P.; Capobianco, A.; Falco, M.; Lanino, E.; Pierri, I.; Zambello, R.; et al. Analysis of the receptor-ligand interactions in the natural killer-mediated lysis of freshly isolated myeloid or lymphoblastic leukemias: Evidence for the involvement of the Poliovirus receptor (CD155) and Nectin-2 (CD112). Blood 2005, 105, 2066-2073. [CrossRef] [PubMed]

14. Willem, C.; Makanga, D.R.; Guillaume, T.; Maniangou, B.; Legrand, N.; Gagne, K.; Peterlin, P.; Garnier, A.; Béné, M.C.; Cesbron, A.; et al. Impact of KIR/HLA Incompatibilities on NK Cell Reconstitution and Clinical Outcome after T Cell-Replete Haploidentical Hematopoietic Stem Cell Transplantation with Posttransplant Cyclophosphamide. J. Immunol. 2019, 202, 2141-2152. [CrossRef]

15. Parham, P. Co-evolution of lymphocyte receptors with MHC class I. Immunol. Rev. 2015, 267, 1-5. [CrossRef]

16. Björkström, N.K.; Riese, P.; Heuts, F.; Andersson, S.; Fauriat, C.; Ivarsson, M.A.; Björklund, A.T.; Flodström-Tullberg, M.; Michaëlsson, J.; Rottenberg, M.E.; et al. Expression patterns of NKG2A, KIR, and CD57 define a process of CD56dim NK-cell differentiation uncoupled from NK-cell education. Blood 2010, 116, 3853-3864. [CrossRef]

17. Nielsen, C.M.; White, M.J.; Goodier, M.R.; Riley, E.M. Functional Significance of CD57 Expression on Human NK Cells and Relevance to Disease. Front. Immunol. 2013, 4. [CrossRef]

18. Pfefferle, A.; Jacobs, B.; Netskar, H.; Ask, E.H.; Lorenz, S.; Clancy, T.; Goodridge, J.P.; Sohlberg, E.; Malmberg, K.-J. Intra-lineage Plasticity and Functional Reprogramming Maintain Natural Killer Cell Repertoire Diversity. Cell Rep. 2019, 29, 2284-2294.e4. [CrossRef]

19. Cichocki, F.; Grzywacz, B.; Miller, J.S. Human NK Cell Development: One Road or Many? Front. Immunol. 2019, 10. [CrossRef]

20. Béziat, V.; Liu, L.L.; Malmberg, J.-A.; Ivarsson, M.A.; Sohlberg, E.; Björklund, A.T.; Retière, C.; Sverremark-Ekström, E.; Traherne, J.; Ljungman, P.; et al. NK cell responses to cytomegalovirus infection lead to stable imprints in the human KIR repertoire and involve activating KIRs. Blood 2013, 121, 2678-2688. [CrossRef]

21. Della Chiesa, M.; Muccio, L.; Moretta, A. CMV induces rapid NK cell maturation in HSCT recipients. Immunol. Lett. 2013, 155, 11-13. [CrossRef] [PubMed]

22. Foley, B.; Cooley, S.; Verneris, M.R.; Curtsinger, J.; Luo, X.; Waller, E.K.; Anasetti, C.; Weisdorf, D.; Miller, J.S. Human Cytomegalovirus (CMV)-Induced Memory-like NKG2C ${ }^{+}$NK Cells Are Transplantable and Expand In Vivo in Response to Recipient CMV Antigen. J. Immunol. 2012, 189, 5082-5088. [CrossRef] [PubMed]

23. Djaoud, Z.; David, G.; Bressollette, C.; Willem, C.; Rettman, P.; Gagne, K.; Legrand, N.; Mehlal, S.; Cesbron, A.; Imbert-Marcille, B.-M.; et al. Amplified NKG2C+ NK Cells in Cytomegalovirus (CMV) Infection Preferentially Express Killer Cell Ig-like Receptor 2DL: Functional Impact in Controlling CMV-Infected Dendritic Cells. J. Immunol. 2013, 191, 2708-2716. [CrossRef] [PubMed] 
24. Hammer, Q.; Rückert, T.; Borst, E.M.; Dunst, J.; Haubner, A.; Durek, P.; Heinrich, F.; Gasparoni, G.; Babic, M.; Tomic, A.; et al. Peptide-specific recognition of human cytomegalovirus strains controls adaptive natural killer cells. Nat. Immunol. 2018, 19, 453-463. [CrossRef] [PubMed]

25. Fehniger, T.A.; Cooper, M.A. Harnessing NK Cell Memory for Cancer Immunotherapy. Trends Immunol. 2016, 37, 877-888. [CrossRef]

26. Torelli, G.F.; Peragine, N.; Raponi, S.; Pagliara, D.; De Propris, M.S.; Vitale, A.; Bertaina, A.; Barberi, W.; Moretta, L.; Basso, G.; et al. Recognition of adult and pediatric acute lymphoblastic leukemia blasts by natural killer cells. Haematologica 2014, 99, 1248-1254. [CrossRef] [PubMed]

27. Locatelli, F.; Moretta, F.; Brescia, L.; Merli, P. Natural killer cells in the treatment of high-risk acute leukaemia. Semin. Immunol. 2014, 26, 173-179. [CrossRef] [PubMed]

28. Sweeney, C.; Vyas, P. The Graft-Versus-Leukemia Effect in AML. Front. Oncol. 2019, 9. [CrossRef]

29. Paczulla, A.M.; Rothfelder, K.; Raffel, S.; Konantz, M.; Steinbacher, J.; Wang, H.; Tandler, C.; Mbarga, M.; Schaefer, T.; Falcone, M.; et al. Absence of NKG2D ligands defines leukaemia stem cells and mediates their immune evasion. Nature 2019, 572, 254-259. [CrossRef]

30. David, G.; Djaoud, Z.; Willem, C.; Legrand, N.; Rettman, P.; Gagne, K.; Cesbron, A.; Retière, C. Large Spectrum of HLA-C Recognition by Killer Ig-like Receptor (KIR)2DL2 and KIR2DL3 and Restricted C1 Specificity of KIR2DS2: Dominant Impact of KIR2DL2/KIR2DS2 on KIR2D NK Cell Repertoire Formation. J. Immunol. 2013, 191, 4778-4788. [CrossRef]

31. Hansasuta, P.; Dong, T.; Thananchai, H.; Weekes, M.; Willberg, C.; Aldemir, H.; Rowland-Jones, S.; Braud, V.M. Recognition of HLA-A3 and HLA-A11 by KIR3DL2 is peptide-specific. Eur. J. Immunol. 2004, 34, 1673-1679. [CrossRef] [PubMed]

32. Morvan, M.; David, G.; Sébille, V.; Perrin, A.; Gagne, K.; Willem, C.; Kerdudou, N.; Denis, L.; Clémenceau, B.; Folléa, G.; et al. Autologous and allogeneic HLA KIR ligand environments and activating KIR control KIR NK-cell functions. Eur. J. Immunol. 2008, 38, 3474-3486. [CrossRef]

33. Fauriat, C.; Andersson, S.; Björklund, A.T.; Carlsten, M.; Schaffer, M.; Björkström, N.K.; Baumann, B.C.; Michaëlsson, J.; Ljunggren, H.-G.; Malmberg, K.-J. Estimation of the Size of the Alloreactive NK Cell Repertoire: Studies in Individuals Homozygous for the Group A KIR Haplotype. J. Immunol. 2008, 181, 6010-6019. [CrossRef] [PubMed]

34. Yu, J.; Heller, G.; Chewning, J.; Kim, S.; Yokoyama, W.M.; Hsu, K.C. Hierarchy of the Human Natural Killer Cell Response Is Determined by Class and Quantity of Inhibitory Receptors for Self-HLA-B and HLA-C Ligands. J. Immunol. 2007, 179, 5977-5989. [CrossRef]

35. Hilton, H.G.; Guethlein, L.A.; Goyos, A.; Nemat-Gorgani, N.; Bushnell, D.A.; Norman, P.J.; Parham, P. Polymorphic HLA-C Receptors Balance the Functional Characteristics of KIR Haplotypes. J. Immunol. 2015, 195, 3160-3170. [CrossRef] [PubMed]

36. Morvan, M.; Willem, C.; Gagne, K.; Kerdudou, N.; David, G.; Sébille, V.; Folléa, G.; Bignon, J.-D.; Retière, C. Phenotypic and Functional Analyses of KIR3DL1+ and KIR3DS1+ NK Cell Subsets Demonstrate Differential Regulation by Bw4 Molecules and Induced KIR3DS1 Expression on Stimulated NK Cells. J. Immunol. 2009, 182, 6727-6735. [CrossRef]

37. Goodridge, J.P.; Önfelt, B.; Malmberg, K.-J. Newtonian cell interactions shape natural killer cell education. Immunol. Rev. 2015, 267, 197-213. [CrossRef] [PubMed]

38. Hatton, O.; Strauss-Albee, D.M.; Zhao, N.Q.; Haggadone, M.D.; Pelpola, J.S.; Krams, S.M.; Martinez, O.M.; Blish, C.A. NKG2A-Expressing Natural Killer Cells Dominate the Response to Autologous Lymphoblastoid Cells Infected with Epstein-Barr Virus. Front. Immunol. 2016, 7. [CrossRef]

39. Forslund, E.; Sohlberg, E.; Enqvist, M.; Olofsson, P.E.; Malmberg, K.-J.; Önfelt, B. Microchip-Based Single-Cell Imaging Reveals That CD56 ${ }^{\text {dim }}$ CD57- KIR $^{-}$NKG2A ${ }^{+}$NK Cells Have More Dynamic Migration Associated with Increased Target Cell Conjugation and Probability of Killing Compared to CD56 ${ }^{\text {dim }}$ CD57 $^{-}$KIR $^{-}$ NKG2A ${ }^{-}$NK Cells. J. Immunol. 2015, 195, 3374-3381. [CrossRef]

40. Russo, A.; Oliveira, G.; Berglund, S.; Greco, R.; Gambacorta, V.; Cieri, N.; Toffalori, C.; Zito, L.; Lorentino, F.; Piemontese, S.; et al. NK cell recovery after haploidentical HSCT with posttransplant cyclophosphamide: Dynamics and clinical implications. Blood 2018, 131, 247-262. [CrossRef]

41. Mancusi, A.; Ruggeri, L.; Velardi, A. Haploidentical hematopoietic transplantation for the cure of leukemia: From its biology to clinical translation. Blood 2016, 128, 2616-2623. [CrossRef] 
42. Locatelli, F.; Pende, D.; Mingari, M.C.; Bertaina, A.; Falco, M.; Moretta, A.; Moretta, L. Cellular and molecular basis of haploidentical hematopoietic stem cell transplantation in the successful treatment of high-risk leukemias: Role of alloreactive NK cells. Front. Immunol. 2013, 4. [CrossRef]

43. Nguyen, S.; Dhedin, N.; Vernant, J.-P.; Kuentz, M.; Jijakli, A.A.; Rouas-Freiss, N.; Carosella, E.D.; Boudifa, A.; Debré, P.; Vieillard, V. NK-cell reconstitution after haploidentical hematopoietic stem-cell transplantations: Immaturity of NK cells and inhibitory effect of NKG2A override GvL effect. Blood 2005, 105, 4135-4142. [CrossRef] [PubMed]

44. Hodgins, J.J.; Khan, S.T.; Park, M.M.; Auer, R.C.; Ardolino, M. Killers 2.0: NK Cell Therapies at the Forefront of Cancer Control. Available online: http://www.jci.org/articles/view/129338/pdf (accessed on 7 May 2020).

45. Ruggeri, L.; Parisi, S.; Urbani, E.; Curti, A. Alloreactive Natural Killer Cells for the Treatment of Acute Myeloid Leukemia: From Stem Cell Transplantation to Adoptive Immunotherapy. Front. Immunol. 2015, 6. [CrossRef] [PubMed]

46. Liu, E.; Marin, D.; Banerjee, P.; Macapinlac, H.A.; Thompson, P.; Basar, R.; Kerbauy, L.N.; Overman, B.; Thall, P.; Kaplan, M.; et al. Use of CAR-Transduced Natural Killer Cells in CD19-Positive Lymphoid Tumors. N. Engl. J. Med. 2020. [CrossRef] [PubMed]

47. Manser, A.R.; Scherenschlich, N.; Thöns, C.; Hengel, H.; Timm, J.; Uhrberg, M. KIR Polymorphism Modulates the Size of the Adaptive NK Cell Pool in Human Cytomegalovirus-Infected Individuals. J. Immunol. 2019, 203, 2301-2309. [CrossRef]

48. Liu, L.L.; Béziat, V.; Oei, V.Y.S.; Pfefferle, A.; Schaffer, M.; Lehmann, S.; Hellström-Lindberg, E.; Söderhäll, S.; Heyman, M.; Grandér, D.; et al. Ex Vivo Expanded Adaptive NK Cells Effectively Kill Primary Acute Lymphoblastic Leukemia Cells. Cancer Immunol. Res. 2017, 5, 654-665. [CrossRef]

49. Lopez-Verges, S.; Milush, J.M.; Schwartz, B.S.; Pando, M.J.; Jarjoura, J.; York, V.A.; Houchins, J.P.; Miller, S.; Kang, S.-M.; Norris, P.J.; et al. Expansion of a unique CD57+NKG2Chi natural killer cell subset during acute human cytomegalovirus infection. Proc. Natl. Acad. Sci. USA 2011, 108, 14725-14732. [CrossRef]

50. Merino, A.; Zhang, B.; Dougherty, P.; Luo, X.; Wang, J.; Blazar, B.R.; Miller, J.S.; Cichocki, F. Chronic stimulation drives human NK cell dysfunction and epigenetic reprograming. J. Clin. Invest. 2019, 129, 3770-3785. [CrossRef]

51. Sun, J.Y.; Gaidulis, L.; Miller, M.M.; Goto, R.M.; Rodriguez, R.; Forman, S.J.; Senitzer, D. Development of a multiplex PCR-SSP method for Killer-cell immunoglobulin-like receptor genotyping. Tissue Antigens 2004, 64, 462-468. [CrossRef]

52. Alter, G.; Malenfant, J.M.; Altfeld, M. CD107a as a functional marker for the identification of natural killer cell activity. J. Immunol. Methods 2004, 294, 15-22. [CrossRef]

53. Penack, O.; Gentilini, C.; Fischer, L.; Asemissen, A.M.; Scheibenbogen, C.; Thiel, E.; Uharek, L. CD56dimCD16neg cells are responsible for natural cytotoxicity against tumor targets. Leukemia 2005, 19, 835-840. [CrossRef]

54. Sturn, A.; Quackenbush, J.; Trajanoski, Z. Genesis: Cluster analysis of microarray data. Bioinformatics 2002, 18, 207-208. [CrossRef]

55. Hsu, K.C.; Chida, S.; Geraghty, D.E.; Dupont, B. The killer cell immunoglobulin-like receptor (KIR) genomic region: Gene-order, haplotypes and allelic polymorphism. Immunol. Rev. 2002, 190, 40-52. [CrossRef]

(C) 2020 by the authors. Licensee MDPI, Basel, Switzerland. This article is an open access article distributed under the terms and conditions of the Creative Commons Attribution (CC BY) license (http://creativecommons.org/licenses/by/4.0/). 